OPEN ACCESS

Editors' Choice-Washing of Nickel-Rich Cathode Materials for LithiumIon Batteries: Towards a Mechanistic Understanding

To cite this article: Daniel Pritzl et al 2019 J. Electrochem. Soc. 166 A4056

View the article online for updates and enhancements. 


\title{
Washing of Nickel-Rich Cathode Materials for Lithium-Ion Batteries: Towards a Mechanistic Understanding
}

\author{
Daniel Pritzl, $@ 1,=, *$ Tobias Teufl, ${ }^{1,2,=, *, z}$ Anna T. S. Freiberg, ${ }^{1, *}$ Benjamin Strehle, ${ }^{1, *}$ \\ Johannes Sicklinger, $\circledast^{1, *}$ Heino Sommer, ${ }^{2}$ Pascal Hartmann, ${ }^{2}$ and Hubert A. Gasteiger ${ }^{1, * *}$
}

${ }^{I}$ Chair of Technical Electrochemistry, Department of Chemistry and Catalysis Research Center, Technical University of Munich, Munich, Germany

${ }^{2}$ BASF SE, New Battery Materials and Systems, Ludwigshafen, Germany

\begin{abstract}
Washing is a commonly used method to remove surface impurities of cathode materials for lithium-ion batteries. However, a clear mechanistic understanding of the washing process is missing in the literature. In this study, we will investigate the effect of washing and subsequent drying of nickel-rich NCM cathodes (85\% nickel) with respect to gassing and impedance of the washed cathodes. By on-line electrochemical mass spectrometry (OEMS), we will show a drastic reduction of the $\mathrm{O}_{2}$ release above $80 \%$ SOC for the NCM washed with deionized water, suggesting the formation of an oxygen-depleted surface layer on the NCM particle surface. The modification of the surface can be confirmed by a strong impedance buildup of cathodes composed of washed NCM (using a microreference electrode in a full-cell), revealing that the impedance increases strongly with increasing drying temperature after washing. Last, we will propose a comprehensive mechanism on the processes occurring during the washing/drying process of nickel-rich NCM materials and identify the drying temperature after washing as the dominant factor influencing the surface properties.

(C) The Author(s) 2019. Published by ECS. This is an open access article distributed under the terms of the Creative Commons Attribution 4.0 License (CC BY, http://creativecommons.org/licenses/by/4.0/), which permits unrestricted reuse of the work in any medium, provided the original work is properly cited. [DOI: 10.1149/2.1351915jes]

(c))BY
\end{abstract}

Manuscript submitted October 18, 2019; revised manuscript received November 8, 2019. Published December 3, 2019. This was Paper 234 presented at the Cancun, Mexico, Meeting of the Society, September 30-October 4, 2018.

Lithium-ion batteries are considered as a viable option to power electric vehicles (EVs), but several obstacles like too high battery cost and insufficient EV driving range still have to be overcome. ${ }^{1,2}$ In principle, this can be addressed by increasing the energy density of future lithium-ion batteries, which most critically depends on the capacity of the cathode active material (CAM). ${ }^{2}$ One of the most promising class of cathode materials to enable higher capacities are the socalled NCM and NCA materials, both having a layered structure with the sum formula $\mathrm{LiMeO}_{2}(\mathrm{Me}=\mathrm{Ni}, \mathrm{Co}, \mathrm{Mn}$ for $\mathrm{NCM}$, and $\mathrm{Me}=$ $\mathrm{Ni}, \mathrm{Co}, \mathrm{Al}$ for NCA). In current vehicles, for example, NCM-523 (Ni:Co:Mn = 5:2:3) cathodes are used, ${ }^{3}$ showing good structural stability during lithium extraction/insertion as well as reasonable capacities of $\approx 160 \mathrm{mAh} / \mathrm{g}$. ${ }^{3}$ However, higher nickel contents are required to increase the specific capacity at acceptable upper cut-off voltages, represented by nickel-rich NCMs like NCM-811 (Ni:Co:Mn = 8:1:1) or with even higher nickel content. ${ }^{4}$ These nickel-rich NCMs can provide reversible capacities exceeding $180 \mathrm{mAh} / \mathrm{g}$ at reasonable cut-off potentials ( $4.2 \mathrm{~V}$ vs. graphite). For these nickel-rich materials manganese and aluminum can be used to stabilize the structure, ${ }^{5}$ using aluminum leads to nickel-rich NCA, which is used by Tesla since many years. ${ }^{3}$

However, the increasing capacity of nickel-rich materials comes at the cost of faster capacity fading and higher sensitivity toward exposure or storage of the materials at ambient air. ${ }^{6,7}$ It was shown that $\mathrm{Ni}$-rich materials are very sensitive toward storage under humidity and $\mathrm{CO}_{2}$ containing atmospheres, ${ }^{6-9}$ leading to the formation of large amounts of hydroxides and carbonates on the surface of the CAM particles. ${ }^{10-17}$ These surface impurities do not only lead to a deterioration of the capacity retention ${ }^{6,8,9}$ and to substantial gassing during cell cycling, ${ }^{8,18-21}$ but also lead to a high $\mathrm{pH}$ of the electrode coating slurries, which can cause gelation of the slurry during electrode preparation. ${ }^{17,22} \mathrm{~A}$ simple and practical approach to remove surface contaminants taken by cell and material manufacturers is a washing step, in which the cathode active material is washed in an aqueous solution. ${ }^{17,23}$ This washing step can significantly lower the $\mathrm{pH}$ value of the coating slurry ${ }^{17,24}$ and can thus prevent gelation during the electrode coating process. $\mathrm{Kim}^{25}$ has also shown that washing of nickelrich cathodes can efficiently prevent gas evolution during high temperature storage experiments. It has initially been suggested that washing

\footnotetext{
$=$ These authors contributed equally to this work

*Electrochemical Society Student Member.

**Electrochemical Society Fellow.

${ }^{\mathrm{z}}$ E-mail: tobias-maximilian.teufl@basf.com
}

of NCA improves its properties by simply removing lithium carbonate and lithium hydroxide impurities from the CAM surface, ${ }^{24}$ whereas other reports suggest also a reaction of water in the wash solution with the active material itself. ${ }^{17,26}$

While the removal of lithium carbonate surface impurities from NCA by washing clearly reduces the gassing upon high-temperature storage, ${ }^{24,25}$ the effect of washing on the cycle life of Ni-rich CAMs is less clear. For example, Kim et al. ${ }^{24}$ showed that room temperature washing of NCA followed by re-calcination at $700^{\circ} \mathrm{C}$ significantly improves the overall capacity and capacity retention for cycling conducted at low C-rates $(0.3 \mathrm{C})$ and at $25^{\circ} \mathrm{C} .{ }^{24}$ Similarly, Xiong et al. ${ }^{26}$ showed that a washed NCM-811 re-calcined at $700^{\circ} \mathrm{C}$ also exhibits superior capacity retention compared to an unwashed material (cycling at $2 \mathrm{C}$ and $25^{\circ} \mathrm{C}$ ), even though its initial capacity is slightly lower. On the other hand, Kim et al. ${ }^{17}$ report a negative effect of washing on the cycling stability of NCA (cycling at $1 \mathrm{C}$ and $45^{\circ} \mathrm{C}$ ); unfortunately, since the washing process (e.g., water/CAM ratio, temperature, etc.) and the subsequent drying/calcination temperature were not specified, it is not possible to determine whether this negative effect of washing is due to the washing/drying procedure or due to the higher cycling temperature. While one would expect that an NCM surface without any hydroxides or carbonates should perform best, some work suggests that synthesis of a material with an entirely virgin surface shows poor electrochemistry, and that a certain exposure to ambient conditions is required to create a stable surface. ${ }^{11}$

With regards to the structural evolution of nickel-rich CAMs, it has been shown that nickel-rich NCMs tend to form a spinel-type surface structure at high state-of-charge (SOC $>80 \%)$ induced by oxygen release, ${ }^{27,28}$ ultimately leading to chemical electrolyte oxidation ${ }^{29}$ and a substantial impedance build-up ${ }^{27}$ (the same was observed for Liand $\mathrm{Mn}$-rich $\mathrm{NCMs}^{30}$ ). At the moment, many different surface stabilizations strategies are under investigation to stabilize the surface of nickel-rich layered cathode materials, such as surface sulfatation, ${ }^{31,32}$ recalcination after exposure to the ambient, ${ }^{8,9,33}$ as well as surface coatings with spinel structures ${ }^{34}$ or core-shell particles. ${ }^{35}$ Considering the results by Paulsen et al., ${ }^{11}$ we suggest that washing of nickel-rich materials does not only remove the well-known $\mathrm{Li}_{2} \mathrm{CO}_{3}$ and $\mathrm{LiOH}$ surface impurities, but also modifies the near-surface bulk properties of Ni-rich CAMs by an $\mathrm{Li}^{+} / \mathrm{H}^{+}$ion exchange between the CAM and the wash solution, ${ }^{9,36,37}$ which particularly in the subsequent drying/recalcination step might lead to very different near-surface structures. While washing of nickel-rich cathode materials (mostly NCA) is a well-known industrial process and is already implemented by most of 
the battery manufacturers, the effect of these washing procedures and of the subsequent drying/recalcination step on the CAM properties is still not clearly understood. More detailed insights into these processes might ultimately reveal improved surface modification strategies for nickel-rich cathode active materials.

In this study we will examine the reactions that occur during the washing of the nickel-rich cathode active material $\mathrm{LiNi}_{0.85} \mathrm{Co}_{0.10} \mathrm{Mn}_{0.05} \mathrm{O}_{2}$ (referred to as NCM-851005) in deionized water and during the subsequent drying/heating step. Subsequently, the effect of the washing/drying procedure on the electrochemical properties will be examined. By means of on-line electrochemical mass spectrometry (OEMS) we could prove that washing/drying has a significant influence on the oxygen release and the overall gas evolution of NCM-851005 during the first charge, which can be rationalized by the formation of an oxygen deficient surface layer during the drying step. While titration analysis of the wash solution and X-ray photoelectron spectroscopy (XPS) of washed NCM-851005 shows that washing with water can remove lithium hydroxide and carbonate impurities from the surface without releasing oxygen (demonstrated by on-line mass spectrometry), we can clearly show by electrochemical impedance spectroscopy (EIS) and OEMS that the drying temperature most strongly affects the properties of the newly formed NCM-851005 surface. Its effect on the cycling stability of graphite/NCM-851005 full-cells will be discussed.

\section{Experimental}

Washing process of NCM-851005 powder.-For the washing process, $20 \mathrm{~g}$ of NCM-851005 (from BASF SE, Germany) were mixed with $100 \mathrm{~mL}$ of deionized water (18 M $\Omega \mathrm{cm}$, Merck KGaA, Germany), and stirred with $700 \mathrm{rpm}$ for 20 minutes at room temperature (referred to as "first washing"). The solution was then filtered, and the washed material was dried under vacuum for 4 hours either at $25^{\circ} \mathrm{C}$ (only for the freeze-dried sample) or at $65^{\circ} \mathrm{C}$ (all other samples). Subsequently, the once washed material was washed again $(20 \mathrm{~g}$ CAM in $100 \mathrm{~mL}$ of deionized water), and the suspension was filtered again (referred to as "second washing").

In a first set of washing experiments, washing was conducted in an argon-filled glove box, and the filtered sample after the first washing step was dried under vacuum at $65^{\circ} \mathrm{C}$ for 4 hours. The $\mathrm{pH}$ values in the CAM/water slurry were measured as a function of time during the first and the second washing step. In addition, the concentrations of $\mathrm{LiOH}$ and $\mathrm{Li}_{2} \mathrm{CO}_{3}$ in the filtrated wash solutions after the first and second washing were determined by titration with $\mathrm{HCl} . \mathrm{Li}_{2} \mathrm{CO}_{3}$ and $\mathrm{LiOH}$ could be distinguished due to the different equivalent points in the titration curve. The twice washed CAM was finally dried under vacuum at $180^{\circ} \mathrm{C}$ for 12 hours.

In a second set of washing experiments, the two washing steps were conducted at ambient atmosphere, drying the CAM in between the two washing steps under vacuum (Büchi oven) at $65^{\circ} \mathrm{C}$ for 4 hours. Parts of the twice washed CAM were then dried under vacuum for 12 hours at three different drying temperatures, namely at $80^{\circ} \mathrm{C}, 180^{\circ} \mathrm{C}$, or $300^{\circ} \mathrm{C}$ under dynamic vacuum (Büchi oven). One batch of twice washed NCM-851005 (dried at $25^{\circ} \mathrm{C}$ between the two washing steps) was dried after the two washing steps at $25^{\circ} \mathrm{C}$ by freeze-drying, for which a vessel with the twice washed CAM was put into liquid nitrogen and dynamic vacuum was applied for 12 hours.

Electrode preparation.-Cathode electrode inks were prepared by dispersing $96 \mathrm{wt} \%$ of the pristine or the washed/dried NCM851005,2 wt $\%$ conductive carbon (Super-C65, Timcal, Switzerland), and $2 \mathrm{wt} \%$ polyvinylene difluoride PVDF binder (Kynar HSV 900, Arkema, France) in N-methyl-2-pyrrolidone NMP (anhydrous, Sigma-Aldrich, USA) using a planetary mixer (Thinky Corp.) for 1015 minutes.

For OEMS measurements, the cathode inks were coated onto a porous stainless-steel mesh (SS316, aperture $26 \mu \mathrm{m}$, wire diameter $25 \mu \mathrm{m}$, The Mesh Company Ltd., UK) and then dried at $50^{\circ} \mathrm{C}$ in a convection oven, the freeze dried cathode coatings were dried at $\approx 25^{\circ} \mathrm{C}$ (ambient temperature) for at least $3 \mathrm{~h}$. The NCM loading was $\approx 12 \mathrm{mg} / \mathrm{cm}^{2}$, corresponding to $\approx 3.3 \mathrm{mAh} / \mathrm{cm}^{2}$ (based on a theoretical capacity of $275 \mathrm{mAh} / \mathrm{g}$ for $100 \%$ delithiation). Cathode electrodes for OEMS experiments were punched out with a diameter of $15 \mathrm{~mm}$.

For impedance and cycling measurements, the cathode inks were coated onto aluminum foil (MTI, $18 \mu \mathrm{m}$ ) with a doctor blade coater and dried afterwards at $50^{\circ} \mathrm{C}$ in a convection oven, the freeze dried cathode coatings were dried at $\approx 25^{\circ} \mathrm{C}$ (ambient temperature) for at least $3 \mathrm{~h}$. The final NCM-851005 coating had a loading of $\approx 9 \mathrm{mg}_{\mathrm{NCM}} / \mathrm{cm}^{2}$, corresponding to $\approx 2 \mathrm{mAh} / \mathrm{cm}^{2}$, based on a first charge capacity of $215 \mathrm{mAh} / \mathrm{g}$ at an upper cell cutoff voltage of $4.2 \mathrm{~V}$ for graphite/NCM851005 full-cells). In this specific case, the theoretical capacity was defined by the first charge capacity in order to guarantee sufficient full-cell balancing. Electrodes with a diameter of $11 \mathrm{~mm}\left(\equiv 0.95 \mathrm{~cm}^{2}\right)$ were punched out and compressed to $\approx 30 \%$ porosity with a $\mathrm{KBr}$ press.

Graphite electrodes were prepared by mixing graphite (commercial, T311, SGL Carbon, Germany) and PVdF at a mass ratio of 95/5 with NMP by applying the same procedure as for the cathode electrodes. The graphite ink was coated onto copper foil (MTI, $12 \mu \mathrm{m})$ and dried in a convection oven at $50^{\circ} \mathrm{C}$ for $3 \mathrm{~h}$. The loading of the graphite coating was $\approx 6 \mathrm{mg}_{\text {graphite }} / \mathrm{cm}^{2}$, corresponding to $\approx 2.05 \mathrm{mAh} / \mathrm{cm}^{2}$ (based on a specific capacity of $\approx 340 \mathrm{mAh} / \mathrm{g}$ ). The electrodes were punched out with a diameter of $11 \mathrm{~mm}$ and compressed to a porosity of $\approx 30 \%$.

Prior to cell assembly (OEMS \& Impedance), anodes were dried under dynamic vacuum at $120^{\circ} \mathrm{C}$. The cathodes were dried at $25^{\circ} \mathrm{C}$ (for the freeze-dried material), at $80^{\circ} \mathrm{C}$ (for the CAM which was dried at $80^{\circ} \mathrm{C}$ prior to coating), or at $120^{\circ} \mathrm{C}$ for all other samples for at least $12 \mathrm{~h}$ in a vacuum oven (Büchi, Switzerland) under dynamic vacuum, and then transferred into an argon-filled glove box (MBraun, Germany) without exposure to air.

On-line electrochemical mass spectrometry (OEMS).-For OEMS experiments, cathode electrodes were coated onto a stainlesssteel mesh (see above), as this porous current collector allows for fast diffusion of evolved gases from the electrode to the flow-restricting capillary leak into the mass spectrometer. ${ }^{38}$ The design of the here used custom-made one-compartment OEMS cell as well as the OEMS setup were reported previously. ${ }^{39}$ OEMS cells were assembled with a $17 \mathrm{~mm}$ diameter lithium metal (from Rockwood Lithium, USA) counter electrode, one glassfiber separator (200 $\mu \mathrm{m}$ thickness, VWR, Germany), an NCM working electrode, and $120 \mu \mathrm{l}$ of electrolyte composed of EC-only with $1.5 \mathrm{M} \mathrm{LiPF}_{6}$ (BASF SE, Germany). The cells were connected to the mass spectrometer, held for $4 \mathrm{~h}$ at $\mathrm{OCV}$ (open circuit voltage), and then charged to $5.0 \mathrm{~V} \mathrm{vs.} \mathrm{Li}^{+} / \mathrm{Li}$ at a $\mathrm{C} / 10$ rate (C-rates here are referenced to a nominal capacity of $275 \mathrm{mAh} / \mathrm{g}$ for complete delithiation). For quantification of the mass spectrometer currents, a calibration gas containing $\mathrm{O}_{2}$ and $\mathrm{CO}_{2}$ (each 2000 ppm) in Argon (Linde AG, Germany) was used. All currents were normalized to the current at $\mathrm{m} / \mathrm{z}=36$ (Ar isotope) in order to correct for effects of minor pressure and temperature changes. The currents $\mathrm{m} / \mathrm{z}=32\left(\mathrm{O}_{2}\right)$ and $\mathrm{m} / \mathrm{z}=44\left(\mathrm{CO}_{2}\right)$ were converted into gas concentration using the cell volume $(\approx 10 \mathrm{~mL})$ and the ideal gas law.

On-line mass spectrometry (OMS).-The above described OEMS setup was modified such that the gas evolution upon the addition of deionized water to the pristine NCM-851005 powder could be examined. For this, the OEMS cell was replaced by a Swagelok T-fitting: one end was connected to the flow-restricting capillary of the MS system, one was equipped with a septum in order to be able to introduce water with a syringe, and one was sealed with a standard closed nut into which $0.5 \mathrm{~g} \mathrm{NCM}-851005$ powder had been added (see inset of Figure 6). The cell was assembled in the glove box and then connected to the flow-restricting capillary of the MS system. Following a 40 minutes rest phase, argon was injected with a syringe in order to check for the tightness of the septum during the injection process. After 60 minutes of recording the mass traces of $\mathrm{O}_{2}, \mathrm{H}_{2} \mathrm{O}$, and $\mathrm{N}_{2}$, $2.5 \mathrm{~mL}$ of purified water were injected into the cell onto the $\mathrm{NCM}$ powder while continuing to monitor the mass signals. 
Electrochemical impedance spectroscopy (EIS) and charge/discharge cycling.-The impedance of the cathode was measured with a micro-reference electrode based on our previously introduced gold wire reference electrode (GWRE) which is integrated into a standard Swagelok T-cell. ${ }^{40}$ After assembly of the cell with a graphite counter electrode, an NCM-851005 working electrode, the GWRE, two glass fiber separator, and $60 \mu 1$ of LP57 electrolyte (from BASF SE, Germany), the GWRE was lithiated using the NCM-851005 working electrode ( $1 \mathrm{~h}$ at $150 \mathrm{nA}$, consuming only $\approx 0.005 \%$ of its capacity). Before measuring the cathode impedance, two formation cycles of the graphite/NCM-851005 full-cells were carried out at $25^{\circ} \mathrm{C}$ between $4.2-3.0 \mathrm{~V}$ cell voltage at a rate of $\mathrm{C} / 10$ (referenced to $215 \mathrm{~mA} / \mathrm{g}$ for the first charge). The formation protocol consisted of a constant-current constant-voltage (CCCV) charge with a cutoff for the $\mathrm{CV}$ phase at $\mathrm{C} / 20$ and a constant-current (CC) discharge. After formation, the cells were charged to $50 \%$ SOC by a $5 \mathrm{~h}$ charge with $\mathrm{C} / 10$ based on the second-cycle discharge capacity. After $1 \mathrm{~h}$ of an OCV rest phase, the cathode impedance was recorded in potentiostatic mode from $100 \mathrm{kHz}$ to $100 \mathrm{mHz}$ with a voltage perturbation of $10 \mathrm{mV}$. Afterwards, charge/discharge cycling at $25^{\circ} \mathrm{C}$ for another 198 cycles was carried out with a CCCV charge to $4.2 \mathrm{~V}$ with $\mathrm{C} / 2$ (cutoff for the $\mathrm{CV}$ phase at $\mathrm{C} / 20$ ) and a $\mathrm{CC}$ discharge to $3.0 \mathrm{~V}$ with $1 \mathrm{C}$.

$X$-ray photoelectron spectroscopy (XPS).-Surface analysis of the pristine and twice washed NCM-851005 (dried at $180^{\circ} \mathrm{C}$ ) was carried out by X-ray photoelectron spectroscopy (Axis, Supra, Kratos, UK). The powders were pressed to pellets inside an argon-filled glove box and mounted onto an electrically insulated sample holder, which can be transferred from the glove box into the XPS system without any air exposure using a transfer chamber (Kratos, UK). The sample was kept in the ante-chamber of the XPS until a pressure of $\approx 10^{-8}$ Torr, and was then transferred to the sample analysis chamber (SAC), where the pressure was always kept below $\approx 10^{-9}$ Torr during the whole measurement period. Sample irradiation was carried out with a monochromated $\mathrm{Al} \mathrm{K} \mathrm{K}_{\alpha}$ radiation $(1486.6 \mathrm{eV}$ ) with an emission current of $15 \mathrm{~mA}$. Survey spectra were recorded for all samples with a stepsize of $0.5 \mathrm{eV}$ and a pass energy (PE) of $160 \mathrm{eV}$. Detailed spectra were recorded with a stepsize of $0.2 \mathrm{eV}$ and a pass energy of $20 \mathrm{eV}$. For all measurements, a charge neutralizer was used, and the spectra were calibrated to the adventitious carbon peak with a binding energy (BE) of $284.8 \mathrm{eV}$.

Thermogravimetric analysis with coupled mass spectrometry (TGA-MS).--For TGA-MS analysis, a TGA system (Mettler Toledo, Switzerland) coupled to a mass spectrometer (Pfeiffer Vacuum, Germany) was used. All samples analyzed by TGA-MS were dried in a vacuum oven (Büchi, Switzerland) for at least $3 \mathrm{~h}$ at $120^{\circ} \mathrm{C}$ under dynamic vacuum. Both pristine NCM-851005 and twice washed NCM851005 (washed in ambient air) dried at $120^{\circ} \mathrm{C}$ after washing were analyzed with the following protocol: First, the TGA-MS was flushed at $25^{\circ} \mathrm{C}$ for 10 minutes with an argon flow rate of $200 \mathrm{~mL} / \mathrm{min}$, followed by reducing the argon flow rate to $20 \mathrm{~mL} / \mathrm{min}$ for 10 minutes. After these pre-treatment steps the TGA-MS analysis was initiated, ramping the temperature from $25^{\circ} \mathrm{C}$ to $120^{\circ} \mathrm{C}$ at $10 \mathrm{~K} / \mathrm{min}$, where it was held for 40 minutes. The actual measurement step was a subsequent temperature ramp at $10 \mathrm{~K} / \mathrm{min}$ to $450^{\circ} \mathrm{C}$, followed by a temperature hold phase of 50 minutes. The $\mathrm{O}_{2}(\mathrm{~m} / \mathrm{z}=32)$ mass traces from the MS were normalized to the nitrogen signal $(\mathrm{m} / \mathrm{z}=28)$. The $\mathrm{H}_{2} \mathrm{O}(\mathrm{m} / \mathrm{z}$ $=18$ ) mass traces were normalized to the first measurement point (no normalization on the nitrogen signal).

\section{Results}

$\mathrm{Li}_{2} \mathrm{CO}_{3} \& \mathrm{LiOH}$ release and $\mathrm{pH}$-value during washing of $\mathrm{NCM}$ 851005.-To study the washing process, we selected the Ni-rich cathode material NCM-851005, as it is known that the formation of surface contaminants, such as $\mathrm{LiOH}$ and $\mathrm{Li}_{2} \mathrm{CO}_{3}$, is most pronounced and has the most detrimental effect on cycle-life for nickel-rich materials. ${ }^{8,9,22}$ In order to obtain accurate values for the amounts of adsorbed $\mathrm{LiOH}$

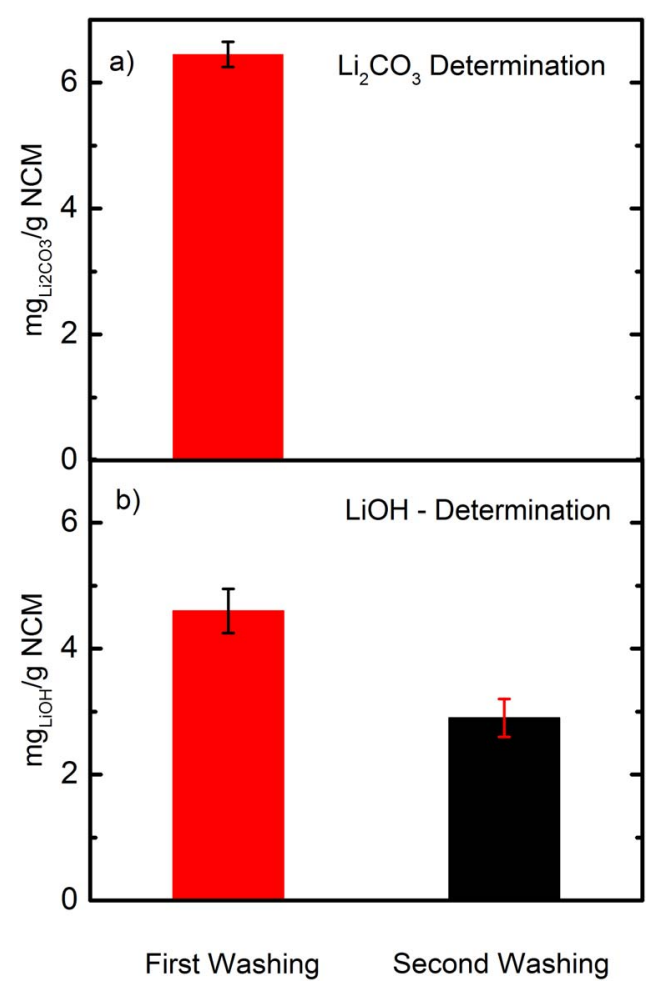

Figure 1. Amounts of a) $\mathrm{Li}_{2} \mathrm{CO}_{3}$ and b) $\mathrm{LiOH}$ determined in the filtrate after the first (red bars) and the second (black bar) washing of NCM-851005 with deionized and degassed water. For each washing step, conducted under argon atmosphere at room temperature, $20 \mathrm{~g}$ NCM-851005 powder was mixed with $100 \mathrm{~mL}$ deionized and degassed water for 20 minutes, and the carbonate and hydroxide amounts were determined by titration with $\mathrm{HCl}$. The error bars show the standard deviation of three repeat measurements.

and $\mathrm{Li}_{2} \mathrm{CO}_{3}$ from the titration analysis of the filtrate after the first washing step as well as for their possible formation in the second washing step, the washing process for the following set of washing experiments was carried out in an argon-filled glove box in order to exclude any effects of $\mathrm{CO}_{2}$ from the air.

Figure 1a shows the lithium carbonate content determined by titration of the washing filtrate. After the first washing step, the amount of lithium carbonate in the wash solution is found to be $6.4 \pm 0.2 \mathrm{mg}_{\mathrm{Li} 2 \mathrm{CO} 3}$ per gram $\mathrm{NCM}$ (red bar). This would correspond to $\approx 0.64 \mathrm{wt} \% \mathrm{Li}_{2} \mathrm{CO}_{3}$ on the surface of the NCM-851005 material (assuming $\mathrm{Li}_{2} \mathrm{CO}_{3}$ to be the main carbonate species), roughly 2 -fold lower than the carbonate impurities of $\approx 1.5 \mathrm{wt} \%$ reported by Noh et al. ${ }^{22}$ for their $85 \%$ nickel containing NCM material $\left(\mathrm{LiNi}_{0.85} \mathrm{Co}_{0.075} \mathrm{Mn}_{0.075} \mathrm{O}_{2}\right)$, quantified by an analogous titration method. The differences in $\mathrm{Li}_{2} \mathrm{CO}_{3}$ content can be due to differences in the synthesis process, the storage conditions of the as-synthesized CAM, and the specific surface areas of the materials. Following the first washing step and drying of the NCM-851005 material in a vacuum oven in the glove box, a second washing step was conducted. Interestingly, no more $\mathrm{Li}_{2} \mathrm{CO}_{3}$ can be detected in the wash solution after the second washing step, which suggests that owing to the high solubility of $\mathrm{Li}_{2} \mathrm{CO}_{3}$ in water, the long washing time and the high water/CAM ratio were sufficient to quantitatively remove all $\mathrm{Li}_{2} \mathrm{CO}_{3}$ impurities within the first washing step under argon atmosphere.

The LiOH content determined by titration after the first washing step is shown in Figure $1 \mathrm{~b}$, corresponding to $4.6 \pm 0.35 \mathrm{mg}_{\mathrm{LiOH}}$ per gram NCM (red bar) or $\approx 0.46 \mathrm{wt} \%$ (assuming LiOH to be the main hydroxide species); in terms of molar quantities, this corresponds to $0.019 \pm 0.001 \mathrm{~mol}_{\mathrm{LiOH}} / \mathrm{mol}_{\mathrm{NCM}-851005}$ based the molecular weight of $97.4 \mathrm{~g} / \mathrm{mol}_{\mathrm{NCM}-851005}$. This again is roughly 2 -fold lower than the $\approx 1.1 \mathrm{wt} \%$ reported by Noh et al. ${ }^{22}$ for their $\mathrm{LiNi}_{0.85} \mathrm{Co}_{0.075} \mathrm{Mn}_{0.075} \mathrm{O}_{2}$ material. Generally, one would expect that 


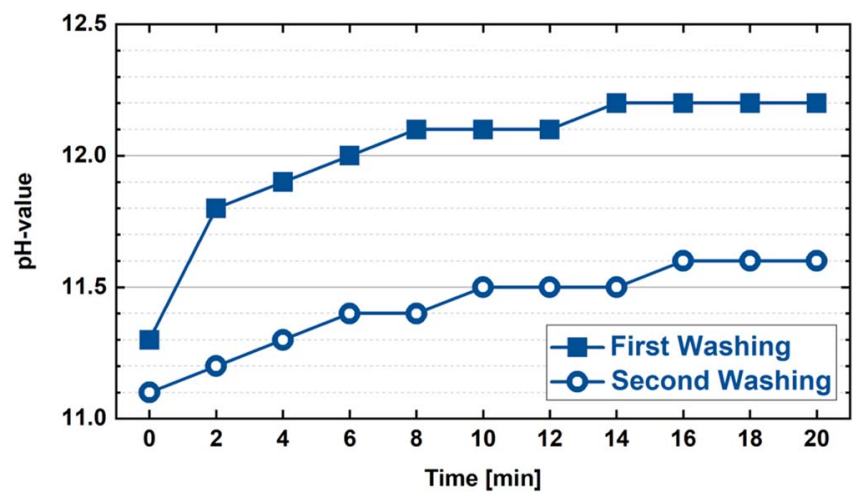

Figure 2. Progression of the $\mathrm{pH}$-value over time for a suspension of $20 \mathrm{~g}$ NCM-851005 in $100 \mathrm{~mL}$ deionized and degassed water while stirring in an argon-filled glove box. The solid squares show the $\mathrm{pH}$-value when pristine NCM-851005 powder is being washed for the first time; the open circles show the $\mathrm{pH}$-value during the second washing of the NCM-851005 powder.

after the first washing step all of the LiOH surface impurities should be removed, as its solubility in water at room temperature is roughly 10-fold higher than that of $\mathrm{Li}_{2} \mathrm{CO}_{3}$. Surprisingly, however, the $\mathrm{LiOH}$ content in the filtrate of the second washing step was still very high, namely $2.8 \pm 0.15 \mathrm{mg}_{\mathrm{LiOH}}$ or $\approx 0.28 \mathrm{wt} \%$ (black bar), equating to $0.011 \pm 0.001 \mathrm{~mol}_{\mathrm{LiOH}} / \mathrm{mol}_{\mathrm{NCM}-851005}$. As $\mathrm{LiOH}$ surface impurities must have been removed in the first washing step, this additional amount of $\mathrm{LiOH}$ must be produced by the washing process itself, presumably by $\mathrm{H}^{+} / \mathrm{Li}^{+}$ion exchange between the solution and the NCM851005 , as will be discussed later. In this case, the total molar fraction of $\mathrm{Li}^{+}$lost from the bulk/near-surface of the NCM-851005 material over the two washing steps would range between $\approx 1.1 \mathrm{~mol} \%$, if the $\mathrm{LiOH}$ in the first washing step would be exclusively from $\mathrm{LiOH}$ surface contaminants, and $\approx 3.0 \mathrm{~mol} \%$ (i.e., sum from first and second washing step), if no $\mathrm{LiOH}$ surface impurities had been present on the pristine NCM-851005 material. This means that during the two washing steps up to $\approx 3 \mathrm{~mol} \%$ of lithium could be lost from the bulk/near-surface of the NCM-851005 material.

The dissolution and to a certain extent formation of $\mathrm{LiOH}$ are also reflected in the change of the $\mathrm{pH}$-value of the wash solution during the first and second washing under argon, as is shown in Figure 2. Upon addition of pristine NCM-851005 powder to the wash solution for the first time (solid squares), the $\mathrm{pH}$ immediately jumps to a value of $\approx 11.3$, and over the course of 20 minutes approaches an essentially constant value of $\approx 12.2$. When the once washed and then dried NCM-851005 powder is subjected to a second washing step, the $\mathrm{pH}$ immediately jumps to a value of $\approx 11.1$ (open circles), similar as in the first washing step, but then levels off at a lower value of $\approx 11.6$ after 20 minutes. While the rapid initial $\mathrm{pH}$ increase in the first washing process could be ascribed to the dissolution of $\mathrm{LiOH}$ surface contaminants, this is unlikely the case for the second washing process, due to the high water solubility of $\mathrm{LiOH}$. Analogous $\mathrm{pH}$ vs. time traces and an analogous lower wash solution $\mathrm{pH}$ for a washed $\mathrm{Ni}$-rich $\mathrm{CAM}$ were already observed by Kim et al. ${ }^{24}$ for NCA with $83 \% \mathrm{Ni}$ and by Xiong et al. ${ }^{26}$ for NCM811. This implies that an initially fast chemical reaction must happen, which over the course of time becomes limited by a slower diffusion process (note that ion transport in the aqueous phase is not expected to be limiting, as the solution was stirred).

The above observed release of $\mathrm{Li}_{2} \mathrm{CO}_{3}$ and $\mathrm{LiOH}$ during the first washing step (Figure 1) accompanied by a rapid $\mathrm{pH}$ increase (Figure 2) is consistent with a dissolution and removal of $\mathrm{Li}_{2} \mathrm{CO}_{3}$ and $\mathrm{LiOH}$ surface impurities from the surface of the NCM-851005 material. However, the continuous more gradual increase of the $\mathrm{pH}$ after its initial rapid increase in the first washing step as well as the release of $\mathrm{LiOH}$ in the second washing step, despite its higher solubility compared to $\mathrm{Li}_{2} \mathrm{CO}_{3}$ that can only be found in the first washing step does suggest a slow but gradual ion exchange between lithium ions from the bulk/near-surface of the NCM structure with protons from the water phase, producing $\mathrm{LiOH}$ dissolved in the aqueous phase, resulting in the observed rise in $\mathrm{pH}$ :

$$
\left.\mathrm{Li}^{+}\right|_{\mathrm{NCM}}+\left.\mathrm{H}_{2} \mathrm{O} \rightarrow \mathrm{H}^{+}\right|_{\mathrm{NCM}}+\mathrm{Li}^{+}+\mathrm{OH}^{-}
$$

In recent work, Shkrob et al. ${ }^{7}$ showed by synchrotron XRD and other analytical methods that an $\mathrm{Li}^{+} / \mathrm{H}^{+}$exchange indeed occurs upon the long-term exposure of NCM-523 to moist air with $100 \%$ relative humidity. While their data are not consistent with the formation of a pure $\gamma$-NiOOH phase that Moshtev et al. ${ }^{41}$ had proposed to be a possible reaction product of $\mathrm{LiNiO}_{2}$ and $\mathrm{H}_{2} \mathrm{O}$, the analysis by Shkrob et al. ${ }^{7}$ suggests a substantial partial ion exchange constituting a sort of intermediate of the pure hydrous oxide phase. Very recently, Jeong et al. ${ }^{42}$ published a study on the effect of washing/drying on the surface properties and the cycle-life of $\mathrm{LiCoO}_{2}$ (LCO) cathode active materials, providing very strong evidence for the near-surface formation of $\mathrm{CoOOH}$, as a result of an $\mathrm{Li}^{+} / \mathrm{H}^{+}$ion exchange. In summary, the above discussion suggests that significant $\mathrm{Li}^{+} / \mathrm{H}^{+}$ion exchange is occurring when Ni-rich NCMs or NCAs as well as LCO are mixed with water, producing a near-surface layer with varying $\mathrm{Li}^{+} / \mathrm{H}^{+}$ratios in the layered oxide structure.

Effect of washing/drying on the first-cycle gas evolution and the cathode impedance.-To examine the effect of washing/drying on the surface properties and the electrochemical performance of NCM851005 , the NCM-851005 material washed twice under argon was heated under vacuum to $180^{\circ} \mathrm{C}$ in order to remove residual water. Whether this would remove residual reactive lithium from the NCM particle surface was then analyzed via XPS, while the effect of washing/drying on the gas evolution in the first charge cycle was determined by on-line electrochemical mass spectrometry (OEMS). Finally, the effect of washing/drying on the cathode charge-transfer resistance was evaluated by electrochemical impedance spectroscopy (EIS) using a gold wire reference electrode (GWRE).

In order to prove that no more residual lithium salts (i.e., $\mathrm{LiOH}$ and $\mathrm{Li}_{2} \mathrm{CO}_{3}$ ) remain on the NCM surface after washing, as claimed by Kim et al., ${ }^{24}$ we performed XPS measurements of the pristine NCM851005 material and the NCM-851005 that was washed twice under argon and was then vacuum dried at $180^{\circ} \mathrm{C}$. The samples were transferred to the vacuum system of the XPS without any exposure to air, using a transfer chamber (Kratos). The Li 1s region was recorded from $52-58 \mathrm{eV}$ binding energy (BE). The top panel of Figure 3 shows the spectrum of the as-received pristine NCM-851005 material. It clearly exhibits two peaks, one centered around $54.0 \mathrm{eV}$ (in green) that we attribute to the intercalated lithium $\left(\mathrm{Li}_{\text {intercalated }}\right)$, and one centered around at $55.3 \mathrm{eV}$ (in blue) that we attribute to lithium salts (i.e., $\mathrm{Li}_{2} \mathrm{CO}_{3}$ and $\mathrm{LiOH})$ on the surface of the pristine NCM-851005 particles ( $\left.\mathrm{Li}_{\text {surface }}\right)$. The assignment of the peaks was further validated by storing the asreceived material in humid air, which resulted in a strong increase of the surface lithium peak (data not shown). On the other hand, when the NCM-851005 powder is washed twice under argon, no more surface lithium can be detected by XPS, whereas the intercalated lithium peak (in green) is still present (see lower panel of Figure 3). This result fits well with the report by Kim et al., ${ }^{24}$ who showed by means of FTIR (Fourier transform infrared) spectroscopic measurements that the amounts of $\mathrm{LiOH}$ and $\mathrm{Li}_{2} \mathrm{CO}_{3}$ drastically decrease after washing of NCA with $83 \% \mathrm{Ni}$. Thus, washing clearly leads to a decrease in residual $\mathrm{LiOH}$ and $\mathrm{Li}_{2} \mathrm{CO}_{3}$ on the surface of Ni-rich CAMs.

Next, we will evaluate whether the washing/drying process has any influence on the initial gassing and the impedance of the NCM851005 material. Recently, it has been shown that oxygen released from the lattice of nickel-rich layered materials at high degree of delithiation (i.e, at high SOC) reacts with the electrolyte, leading to strong gas evolution during the first cycles and to pronounced capacity fading over extended charge/discharge cycling. ${ }^{20,27,29}$ Furthermore, it has been shown that hydroxide species on NCM surfaces react with the electrolyte, accompanied by the formation of $\mathrm{CO}_{2}$ during storage of fully lithiated NCMs in the electrolyte at elevated temperature. ${ }^{8,20}$ In order to investigate the effect of washing/drying on the gas 


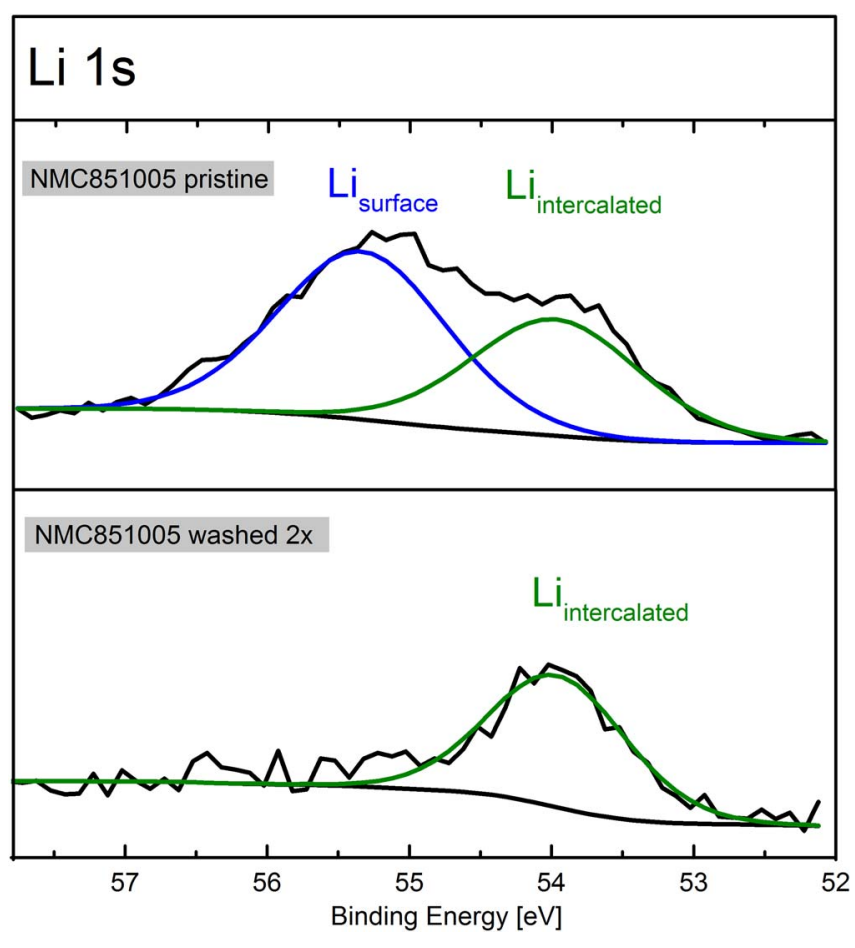

Figure 3. XPS data (in black) from the $\mathrm{Li} 1 \mathrm{~s}$ region of as-received pristine NCM-851005 dried under vacuum at $120^{\circ} \mathrm{C}$ (upper panel) and of NCM851005 washed twice under argon and then dried under vacuum at $180^{\circ} \mathrm{C}$ (lower panel). The samples were transferred from the glove box to the XPS chamber without any air exposure using a transfer chamber. For peak fitting, a Shirley background (black dashed line) was subtracted and two peaks (fitted with a Gauss-Lorentz function (blend $=0.3$ )) with a peak binding energy of $54.0 \mathrm{eV}\left(\mathrm{Li}_{\text {intercalated }}\right.$, green line) and $55.3 \mathrm{eV}\left(\mathrm{Li}_{\text {surface }}\right.$; blue line) and with a FWHM of 1.4 were used.

evolution of a nickel-rich NCM material in the first charge to high SOC, we performed on-line electrochemical mass spectrometry (OEMS) on electrodes with the pristine and the washed NCM-851005. For this, we used a model electrolyte based on pure EC mixed with $1.5 \mathrm{M} \mathrm{LiPF}_{6}$, as it offers two experimental advantages: i) due to its low vapor pressure, an increased signal to noise ratio in the OEMS experiments can be obtained; ${ }^{43}$ ii) the only gases that evolve during EC reduction on the lithium counter electrode are $\mathrm{CO}$ and ethylene, ${ }^{44-46}$ which can be clearly differentiated from the $\mathrm{O}_{2}$ and $\mathrm{CO}_{2}$ evolved from the cathode material. $^{29}$

Results of the OEMS measurements on both samples are shown in Figure 4. The upper panel shows the galvanostatic charge profiles from $\mathrm{OCV}(\approx 3 \mathrm{~V})$ up to $5.0 \mathrm{~V}$ versus a $\mathrm{Li}$ counter electrode, and the middle/lower panels depict the concentration of the concomitantly evolved $\mathrm{O}_{2}(\mathrm{~m} / \mathrm{z}=32$, middle panel $)$ and $\mathrm{CO}_{2}(\mathrm{~m} / \mathrm{z}=44$, lower panel $)$ in units of $\mu \mathrm{mol} / \mathrm{g}_{\mathrm{CAM}}$. The galvanostatic charge profile and the gas evolution for the pristine NCM-851005 is depicted by the gray lines in Figure 4 , showing a capacity of $\approx 267 \mathrm{mAh} / \mathrm{g}$ during the first charge to $5.0 \mathrm{~V} \mathrm{vs}$. $\mathrm{Li}^{+} / \mathrm{Li}$. The onset for $\mathrm{O}_{2}$ evolution can be observed at $\approx 84 \%$ SOC (corresponding to $\approx 4.32 \mathrm{~V}$ vs. $\mathrm{Li}^{+} / \mathrm{Li}$ ), which is consistent with the results reported by Jung et al. ${ }^{20,27}$ for NCM811 and by Teufl et al. ${ }^{30}$ for $\mathrm{HE}-\mathrm{NCM}$. Concomitant with the onset for $\mathrm{O}_{2}$ evolution, a sharp increase in the $\mathrm{CO}_{2}$ evolution can be observed. In contrast to that, the electrode made from the washed NCM-851005 (red lines in Figure 4)

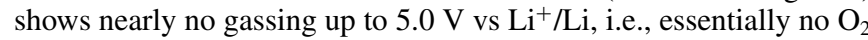
and very little $\mathrm{CO}_{2}$ evolution.

The oxygen release for the pristine NCM-851005 in Figure 4 (middle panel) is in accordance with Streich et al. ${ }^{28}$ and with our previous studies, in which we had shown that the release of lattice oxygen from layered oxides occurs at SOC's exceeding roughly $80 \%$. $^{20,27,28,30,38,47}$ However, concerning the $\mathrm{CO}_{2}$ evolution during the first charge of lay-
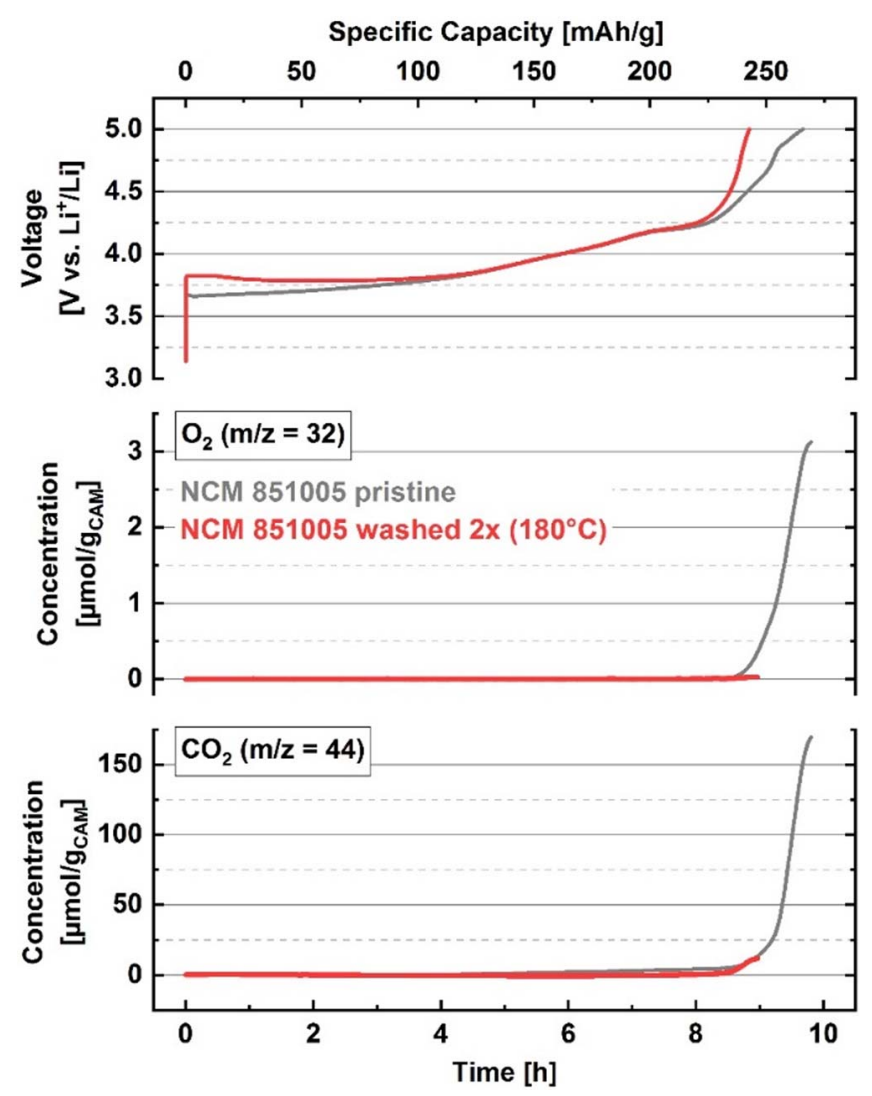

Figure 4. OEMS measurements of the first lithiation cycle to $5.0 \mathrm{~V}$ using Li/NCM-851005 half-cells with the pristine (red lines) and the twice washed NCM-851005 (washed under argon and dried at $180^{\circ} \mathrm{C}$; gray lines). Upper panel: charge voltage vs. time and capacity at a $\mathrm{C} /$ rate of $\mathrm{C} / 10$ (referenced to $275 \mathrm{mAh} / \mathrm{g}$ theoretical delithiation capacity). Middle/lower panels: evolution of the concentrations of evolved $\mathrm{O}_{2} / \mathrm{CO}_{2}$ given in units of $\mu \mathrm{mol} / \mathrm{g}_{\mathrm{CAM}}$. Cells were charged at $25^{\circ} \mathrm{C}$, using a metallic Li counter electrode, a glassfiber separator, and an EC-only electrolyte with $1.5 \mathrm{M} \mathrm{LiPF}_{6}$.

ered oxides, there is an ongoing debate about its origin: i) Luo et al. ${ }^{48}$ assumed that the evolved $\mathrm{CO}_{2}$ is entirely due to electrolyte oxidation with lattice oxygen; ii) Renfrew et al. ${ }^{19}$ proposed the opposite, suggesting that $\mathrm{CO}_{2}$ evolution is exclusively triggered by the oxidative decomposition of $\mathrm{Li}_{2} \mathrm{CO}_{3}$ from surface regions, a statement which was somewhat revised in their later work. ${ }^{49}$ Furthermore, they recently showed that soaking NCM-622 in water can effectively lower the residuals (e.g. $\mathrm{Li}_{2} \mathrm{CO}_{3}$ and $\mathrm{LiOH}$ ) on the surface and thus lower the gassing during cell formation; ${ }^{50}$ iii) Jung et al. ${ }^{27,29}$ suggested that the $\mathrm{CO}_{2}$ evolved at $\approx 4.2 \mathrm{~V} \mathrm{vs}$. $\mathrm{Li}^{+} / \mathrm{Li}$ is produced from surface impurities, while $\mathrm{CO}_{2}$ evolved upon lattice oxygen release at higher potentials would be due to a reaction with the carbonate electrolyte. Recently, Jung et al. ${ }^{20}$ conducted temperature dependent measurements with a ${ }^{13} \mathrm{C}$ labeled electrolyte and NCM622 to better understand the origin of the $\mathrm{CO}_{2}$ evolution at different potentials, revealing a reaction of surface hydroxides with the electrolyte at low potentials as well as a strong reaction of lattice oxygen with the electrolyte and of the resulting acidic electrolyte decomposition species with $\mathrm{Li}_{2} \mathrm{CO}_{3}$ surface contaminants at $>4.3 \mathrm{~V}$ vs. $\mathrm{Li}^{+} / \mathrm{Li}^{20,51}$ For the following discussion, we will adopt the mechanistic view proposed by Jung et al., ${ }^{20}$ who show that the decomposition of $\mathrm{Li}_{2} \mathrm{CO}_{3}$ surface contaminants occurs at the onset of $\mathrm{O}_{2}$ evolution. For this reason, the removal of $\mathrm{Li}_{2} \mathrm{CO}_{3}$ surface contaminants by washing (see Figure 1a) should lower the overall $\mathrm{CO}_{2}$ gassing at high potentials, as already shown for $\mathrm{Ni}$-rich NCAs with $83-85 \% \mathrm{Ni}^{24,25}$ Here, however, one must mention that the electrodes with the washed NCM-851005 were coated at ambient atmosphere, so that small amounts of $\mathrm{Li}_{2} \mathrm{CO}_{3}$ might have been re-formed on its surface prior to cell assembly. As expected, and 
as mentioned above, the difference in the amount of evolved gases between the washed and the pristine NCM-851005 is quite striking (see Figure 4). By the end of the first charge to $5.0 \mathrm{~V}$ vs. $\mathrm{Li}^{+} / \mathrm{Li}$, a total amount of $\approx 3.1 \mu \mathrm{mol} / \mathrm{g}_{\mathrm{CAM}} \mathrm{O}_{2}$ and $\approx 171 \mu \mathrm{mol} / \mathrm{g}_{\mathrm{CAM}} \mathrm{CO}_{2}$ are evolved from the pristine NCM-851005, in stark contrast to only $\approx 0.025 \mu \mathrm{mol} / \mathrm{g}_{\mathrm{CAM}} \mathrm{O}_{2}$ and $\approx 12 \mu \mathrm{mol} / \mathrm{g}_{\mathrm{CAM}} \mathrm{CO}_{2}$ that are evolved from the washed NCM- 851005 (capacity $\approx 244 \mathrm{mAh} / \mathrm{g}$ ), corresponding to $\mathrm{a} \approx 14$-fold lower total gas evolution for the washed/dried NCM-851005. While one could argue that the reduced amount of evolved $\mathrm{CO}_{2}$ after washing of the NCM-851005 might solely be due to a removal of most of the $\mathrm{Li}_{2} \mathrm{CO}_{3}$ surface contaminants (if the $\approx 12 \mu \mathrm{mol} / \mathrm{g}_{\mathrm{CAM}}$ evolved $\mathrm{CO}_{2}$ were entirely due to the decomposition of $\mathrm{Li}_{2} \mathrm{CO}_{3}$ surface contaminants, it would correspond to a reasonable value of $\approx 0.09 \mathrm{wt} \%$ ), the roughly two orders of magnitude lower $\mathrm{O}_{2}$ evolution of the washed NCM-851005 indicates that the surface of the washed NCM-851005 has undergone changes beyond a simple removal of hydroxide and carbonate surface impurities.

As was proven unambiguously by a combination of OEMS and transmission electron microscopy (TEM) in the case of HE-NCM, lattice oxygen release is accompanied by the formation of an oxygendepleted surface layer, which can restructure into a spinel-like surface layer. ${ }^{30}$ Based on OEMS studies, an analogous phenomenon was suggested for $\mathrm{NCMs},{ }^{27,28}$ consistent with the observation of spinel/rocksalt surface layers by TEM measurements after cycling to high potentials and/or high SOC. ${ }^{22,52}$ With this in mind, it is conceivable that the almost complete absence of oxygen evolution from the washed NCM-851005 dried at $180^{\circ} \mathrm{C}$ (see Figure 4) might be caused by the formation of an oxygen-depleted surface layer during the washing/drying process, stabilizing the NCM surface at high SOC. Incidentally, this type of mechanisms has recently been proposed by Jeong et al. ${ }^{42}$ for washed/dried LCO. In this case, the generally expected increase of the impedance of the cathode active material caused by a spinel/rocksalt-like surface layer would have to be observed for the washed/dried NCM-851005 cathode. ${ }^{22,42,53}$ This will be examined in the following cathode impedance analysis.

In order to determine whether the impedance of the NCM-851005 cathode active material is increased by the washing/drying process, graphite/NCM-851005 cells were assembled with a gold wire reference electrode (GWRE). ${ }^{40}$ This micro-reference electrode allows for the recording of artefact-free individual impedance spectra of both the anode and the cathode in full-cells. In this study, cells were assembled with pristine as well as with washed NCM-851005 (washed two times under argon) that was dried at $180^{\circ} \mathrm{C}$ under vacuum. Following two formation cycles at $\mathrm{C} / 10$ and $25^{\circ} \mathrm{C}$ between $3.0-4.2 \mathrm{~V}$, the cells were charged at $\mathrm{C} / 10$ to $50 \%$ SOC referenced to the second discharge capacity (corresponding to $\approx 3.7-3.8 \mathrm{~V}$ cell voltage), where the impedance was recorded (see experimental section for further details). The impedance spectra of the different NCM-851005 cathodes are shown in Figure 5. The partially visible high frequency semi-circle observed in both spectra is attributed to a contact resistance $\left(R_{\text {Contact }}\right)$ between the cathode coating and the aluminum current collector; the low-frequency semi-circle represents the charge-transfer resistance of the NCM-851005 cathode active material $\left(R_{\text {Cathode }}\right)$. More details on this can be found in the work by Landesfeind et al. ${ }^{54}$ The pristine NCM851005 shows a small cathode charge-transfer resistance of $R_{\text {Cathode }} \approx$ $5 \Omega \mathrm{cm}^{2}$ (determined by an R/Q fit). When the same material is washed twice in water and dried under vacuum at $180^{\circ} \mathrm{C}, R_{\text {Cathode }}$ increases by a factor of $\approx 4$ to $\approx 20 \Omega \mathrm{cm}^{2}$. As discussed above, the increase of $R_{\text {Cathode }}$ does suggest the formation of an oxygen-depleted and more resistive surface layer during the washing and/or drying process. Therefore, in the following, we will examine whether oxygen or oxygen-containing species are released during the washing and/or during the drying step of a washed material.

Release of oxygen-containing species during the washing and drying process.-Both, the OEMS data (Figure 4) and the cathode impedance data (Figure 5) suggest that the washing and/or the drying process may lead to an oxygen-depleted surface layer on the NCM851005 particles. Therefore, we will first examine whether oxygen

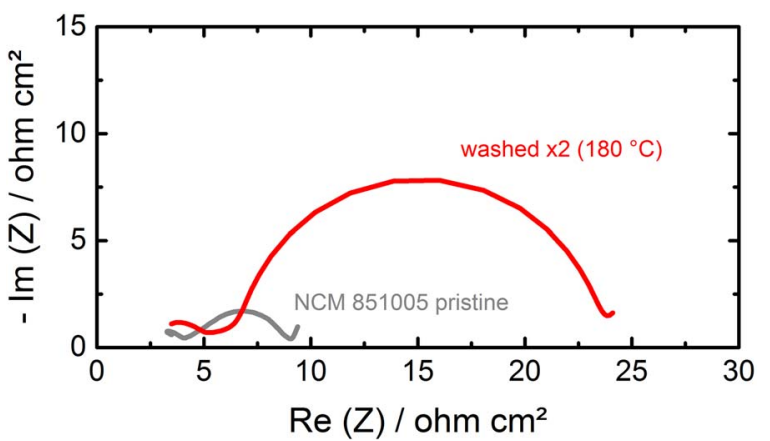

Figure 5. Impedance response of cathode electrodes with pristine NCM851005 (gray) as well as with washed NCM-851005 (washed twice under argon) dried under vacuum at $180^{\circ} \mathrm{C}$ (red) at $50 \%$ SOC and $25^{\circ} \mathrm{C}$. The cathode impedance spectra between $100 \mathrm{kHz}$ and $0.1 \mathrm{~Hz}$ were measured in graphite/NCM-851005 full-cells using a gold-wire reference electrode (GWRE), and were recorded after two formation cycles with $\mathrm{C} / 10$ and a subsequent charge to $50 \%$ SOC (corresponding to $\approx 3.7-3.8 \mathrm{~V}$ cell voltage).

might be released during the washing process. Some evidence for this can be found in the literature. For example, Mosthev et al. ${ }^{41}$ suggested that the extraction of $\mathrm{Li}^{+}$from $\mathrm{LiNiO}_{2}$ cathode active material powder in an aqueous solution would be charge-compensated by the evolution of oxygen from the layered oxide lattice. Furthermore, Liu et al. ${ }^{55}$ investigated the deterioration of $\mathrm{LiNiO}_{2}$ powder under ambient air und suggested that $\mathrm{Ni}^{3+}$ from the lattice would be reduced to $\mathrm{Ni}^{2+}$, with the corresponding oxidation reaction being the oxidation of the lattice oxygen to gaseous $\mathrm{O}_{2}$. If either one of these processes were true, the addition of water to an NCM-851005 powder should lead to the evolution of $\mathrm{O}_{2}$. In order to study this, we used a modified version of our current OEMS setup to conduct an on-line mass spectrometry (OMS) analysis during the washing process. For this, one part of a Swagelok T-fitting was connected to the capillary leading to the MS system (see inset in Figure 6). At one of the other connections, a septum was installed to allow the addition of controlled amounts of water with a syringe, while the remaining connection was equipped with a nut into which NCM-851005 powder was added.

After assembly of the cell in an argon-filled glove box, the mass traces of $\mathrm{O}_{2}(\mathrm{~m} / \mathrm{z}=32)$ and of $\mathrm{H}_{2} \mathrm{O}(\mathrm{m} / \mathrm{z}=18)$ were recorded. The first 40 minutes consisted of a rest period where the signal of residual water decreases and the $\mathrm{O}_{2}$ signal increases slightly. The increase of the oxygen signal is due to a small leakage of the cell (presumably through the septum), as by dividing the mass signal of $\mathrm{N}_{2}(\mathrm{~m} / \mathrm{z}=$ 28 ) by the oxygen signal, a constant time-independent response is obtained, which clearly indicates the slow intrusion of air. After the rest period of 40 minutes, $\approx 2.5 \mathrm{~mL}$ of pure argon (taken from the glove box atmosphere) is injected into the cell in order to verify the tightness of the septum after an injection. One can nicely see that during the penetration of the septum with the needle of the syringe, no increase in the oxygen or water masses are observed. After a total of 100 minutes, $2.5 \mathrm{~mL}$ of water are injected onto the $0.5 \mathrm{~g}$ of the pristine NCM-851005 powder, corresponding to the same water/CAM ratio as in our washing experiments. Consequently, the mass trace for water increases (blue line in Figure 6), but the $\mathrm{O}_{2}$ mass trace (red line) does not increase, clearly indicating that no oxygen evolution occurs when water is added to NCM-851005. Therefore, there is no release of lattice oxygen in form of molecular oxygen from a nickel-rich NCM during washing with water, contrary to the above discussed assumptions in the literature.

Based on the suggested $\mathrm{Li}^{+} / \mathrm{H}^{+}$exchange (see Equation 1), a $\mathrm{NiOOH}$-like structure would be expected to be formed in the nearsurface region of the Ni-rich NCM-851005 particles upon washing. For pure $\mathrm{NiOOH}$, it is known from the literature that it is thermally unstable: at already $\approx 80^{\circ} \mathrm{C}$ it starts to lose water from the interlayers, and at $\approx 260^{\circ} \mathrm{C}$ it is being partially converted to $\mathrm{NiO}$, accompanied by the release of water and oxygen, whereby full conversion to the 


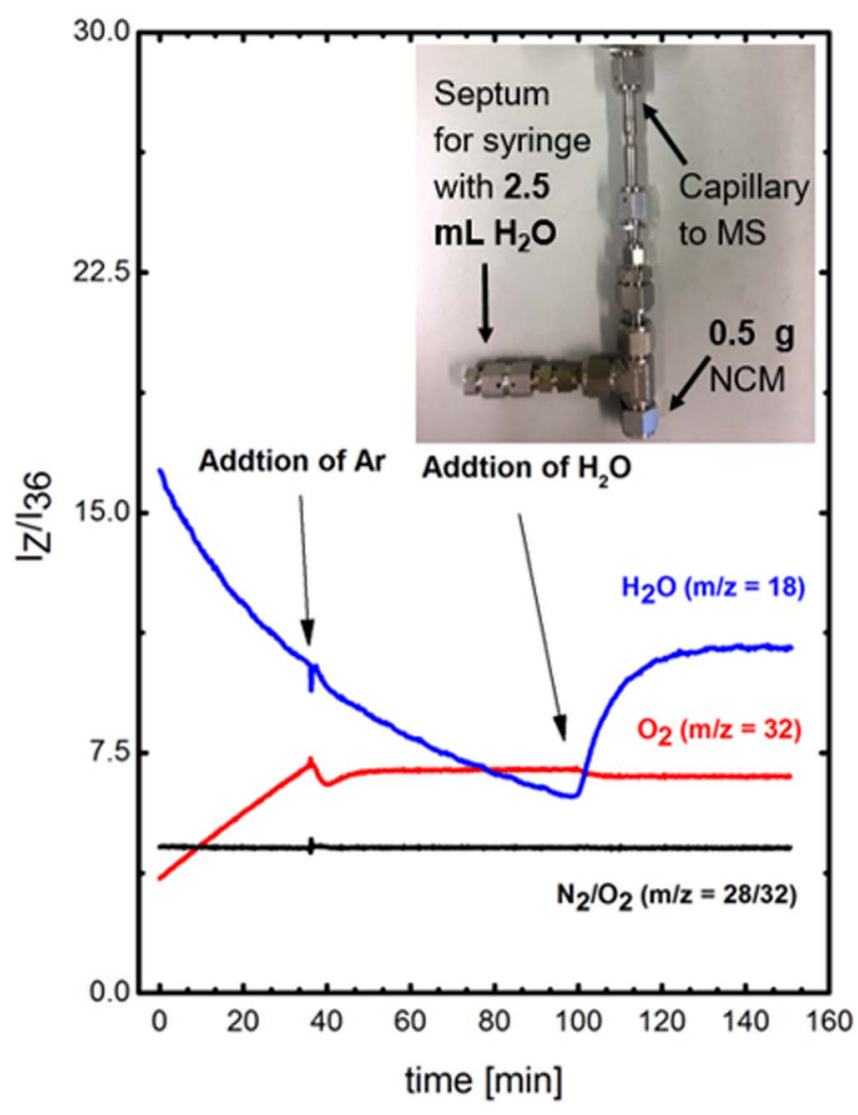

Figure 6. Mass traces of $\mathrm{O}_{2}(\mathrm{~m} / \mathrm{z}=32$, in red $), \mathrm{H}_{2} \mathrm{O}(\mathrm{m} / \mathrm{z}=18$, in blue $)$ and of the $\mathrm{N}_{2} / \mathrm{O}_{2}$ ratio $(\mathrm{m} / \mathrm{z}=28 / 32$, in black) recorded using a modified Swagelok T-cell connected to the MS capillary inlet and containing $0.5 \mathrm{~g}$ pristine NCM851005 powder, placed at the bottom part sealed with a nut (see inset). The first 40 minutes consisted of a rest phase, followed by the addition of pure argon with a syringe through the septum in order to check the stability of the septum. After further 60 minutes (at $\mathrm{t}=100 \mathrm{~min}$ ), $2.5 \mathrm{~mL}$ water were injected with a syringe onto the NCM-851005 powder, and the mass traces were recorded for further 60 minutes.

rocksalt $\mathrm{NiO}$ structure is completed at $\approx 600^{\circ} \mathrm{C} .{ }^{56}$ The complete thermal reduction of the $\mathrm{Ni}^{+3}$ in the $\mathrm{NiOOH}$ phase to $\mathrm{Ni}^{+2}$ in the $\mathrm{NiO}$ rocksalt phase is given as:

$$
2 \mathrm{NiOOH} \rightarrow 2 \text { "NiO" }+0.5 \mathrm{O}_{2}+\mathrm{H}_{2} \mathrm{O}
$$

Based on the described thermally induced transformation of $\mathrm{NiOOH}$, we would expect that heating an NCM-851005 material with a partially $\mathrm{Li}^{+} / \mathrm{H}^{+}$ion exchanged near-surface region formed during washing would lose water and oxygen upon heating. This has actually already been reported for $\mathrm{LiCoO}_{2}$ (LCO) by Jeong et al., ${ }^{42}$ who showed that washing of an LCO cathode active material with water leads to a $\mathrm{CoOOH}$ like structure, which is then thermally decomposed to either a thin $\mathrm{CoO}$ surface layer when dried under air at $400^{\circ} \mathrm{C}$ or to a thicker $\mathrm{Co}_{3} \mathrm{O}_{4}$ surface layer when air-dried at $700^{\circ} \mathrm{C}$. For the latter treatment, the LCO cathode impedance was found to increase substantially.

To further investigate the drying process of washed NCM-851005, which was conducted under vacuum in our experiments (see experimental), we carried out a TGA-MS analysis under a pure argon stream of a pristine and a washed NCM-851005 (washed twice under argon) that was dried under vacuum at $120^{\circ} \mathrm{C}$ during/after washing. Prior to TGA-MS analysis, the NCM samples were dried at $120^{\circ} \mathrm{C}$ under dynamic vacuum for at least $3 \mathrm{~h}$. The TGA-MS protocol consisted of a pre-treatment at $25^{\circ} \mathrm{C}$ to remove physiosorbed water $(10$ minutes at an argon flow rate of $200 \mathrm{~mL} / \mathrm{min}$, followed by 10 minutes at an argon flow rate of $20 \mathrm{~mL} / \mathrm{min}$ ). The actual TGA-MS experiment shown in Figure 7 then was conducted at an argon flow rate of $20 \mathrm{~mL} / \mathrm{min}$ : first,

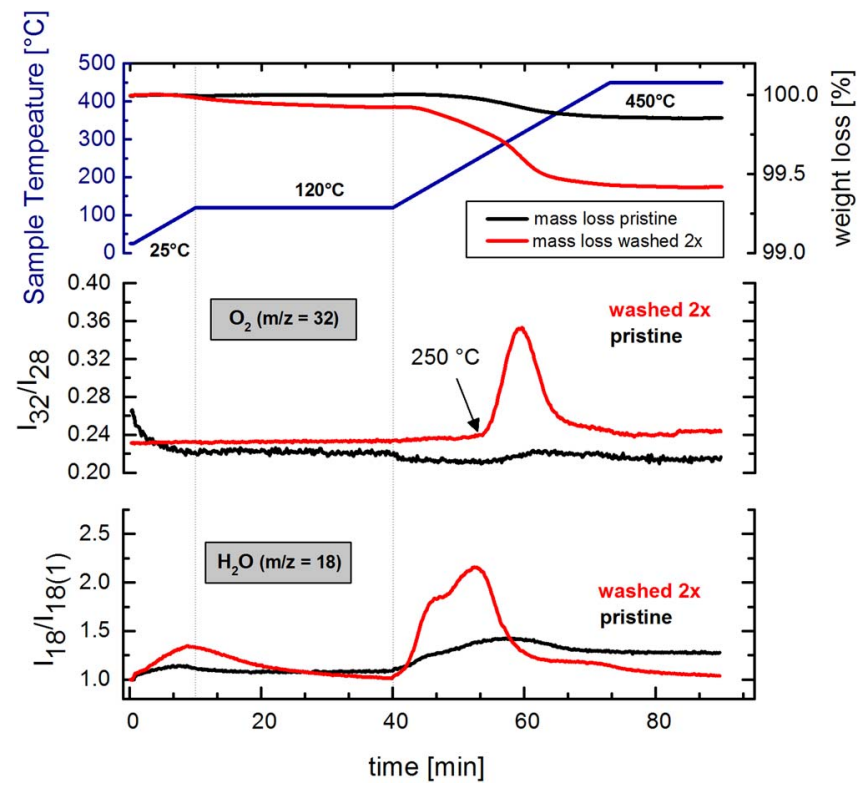

Figure 7. TGA-MS analysis under argon $(20 \mathrm{~mL} /$ minute $)$ of pristine NCM851005 (black lines) and of washed NCM-851005 (twice under argon) that was dried at $65^{\circ} \mathrm{C}$ under vacuum after each washing step (red lines). All materials were dried prior to TGA-MS experiments at $120^{\circ} \mathrm{C}$ under dynamic vacuum for at least $3 \mathrm{~h}$. Top panel: temperature vs. time program with heating ramps and hold phases (blue line, left y-axis) and corresponding mass losses of the pristine and washed NCM (right y-axis). Middle panel: $\mathrm{O}_{2}$ signal $(\mathrm{m} / \mathrm{z}=32)$ normalized by the nitrogen signal $(\mathrm{m} / \mathrm{z}=28)$ in order to exclude artefacts from minute air leaks. Bottom panel: mass traces of water $\mathrm{H}_{2} \mathrm{O}(\mathrm{m} / \mathrm{z}=18)$ normalized by their respective values at the beginning of each measurement sequence (i.e., after the pre-treatment program).

a temperature ramp to $120^{\circ} \mathrm{C}$ at $10 \mathrm{~K} / \mathrm{min}$, then a 40 minute hold phase at $120^{\circ} \mathrm{C}$, and finally a temperature ramp to $450^{\circ} \mathrm{C}(10 \mathrm{~K} / \mathrm{min})$, holding the final temperature for another 20 minutes (see blue line in the upper panel of Figure 7). The results of this experiment are shown in Figure 7. Since the samples were dried at $120^{\circ} \mathrm{C}$ prior to the TGA-MS experiment, no mass losses and only minor amounts of water release were observed during the first temperature ramp from $25^{\circ} \mathrm{C}$ to $120^{\circ} \mathrm{C}$ (see Figure 7). When ramping the temperature from $120^{\circ} \mathrm{C}$ to $450^{\circ} \mathrm{C}$, the pristine NCM-851005 shows a total mass loss of only $\approx 0.1 \mathrm{wt} \%$ that initiates at $\approx 200^{\circ} \mathrm{C}$ (top panel, black line), accompanied only by a weak MS signal for water (bottom panel) and a noticeable absence of $\mathrm{O}_{2}$ release (middle panel). On the other hand, tor the washed NCM851005 , the onset of a first mass loss can be observed somewhat earlier, at $\approx 150^{\circ} \mathrm{C}$ (red lines in Figure 7 ), accompanied by the release of water and an albeit very weak MS signal for released $\mathrm{O}_{2}$. In stark contrast to the pristine NCM-851005, the washed material shows a pronounced release of $\mathrm{O}_{2}$ that initiates at $\approx 250^{\circ} \mathrm{C}$, with a maximum release rate at $\approx 310^{\circ} \mathrm{C}$ (middle panel). This suggests a two-step thermal decomposition reaction for the washed NCM-851005, namely one initiating at $\approx 150^{\circ} \mathrm{C}$ caused by the release of predominantly $\mathrm{H}_{2} \mathrm{O}$, and one initiating at $\approx 250^{\circ} \mathrm{C}$ upon the release of predominantly $\mathrm{O}_{2}$. This seems to be similar to the above described stepwise release of first $\mathrm{H}_{2} \mathrm{O}$ at $\approx 80^{\circ} \mathrm{C}$ and of $\mathrm{H}_{2} \mathrm{O}$ together with $\mathrm{O}_{2}$ at $\approx 260^{\circ} \mathrm{C}$ for $\mathrm{NiOOH}$, as reported by Pan et al.,56 it is also reminiscent of findings by Bak et al., ${ }^{57}$ who reported the initial formation of a disordered $\mathrm{M}_{3} \mathrm{O}_{4}$-type spinel upon heating of partially delithiated NCM-811 $\left(\mathrm{Li}_{0.22} \mathrm{Ni}_{0.8} \mathrm{Co}_{0.1} \mathrm{Mn}_{0.1} \mathrm{O}_{2}\right)$ to $\approx 150^{\circ} \mathrm{C},{ }^{57}$ which upon further heating was shown to decompose to an MO rocksalt phase that is fully formed at $\approx 360^{\circ} \mathrm{C}$. In analogy, it is reasonable to assume that the thermal decomposition of an $\mathrm{H}^{+}$exchanged Ni-rich NCM (i.e., an essentially delithiated NCM in the near-surface region) may also be described in terms of these two principal processes: i) the initial formation of a disordered $\mathrm{M}_{3} \mathrm{O}_{4}$-tupe 
spinel at $\approx 80-150^{\circ} \mathrm{C}$ according to

$$
\mathrm{MOOH} \rightarrow \frac{1}{3} \mathrm{M}_{3} \mathrm{O}_{4}+\frac{1}{2} \mathrm{H}_{2} \mathrm{O}+\frac{1}{12} \mathrm{O}_{2}
$$

where mostly $\mathrm{H}_{2} \mathrm{O}$ is being released; ii) the subsequent release of $\mathrm{O}_{2}$ at $\approx 250-360^{\circ} \mathrm{C}$, resulting in an MO-type rocksalt structure according to

$$
\mathrm{M}_{3} \mathrm{O}_{4} \rightarrow 3 \mathrm{MO}+\frac{1}{2} \mathrm{O}_{2}
$$

The above hypothesized two-step process during drying would be consistent with the two different transition regions vs. temperature observed for the washed NCM-851005 in Figure 7 (i.e., one starting at $\approx 150^{\circ} \mathrm{C}$ and one at $\approx 250^{\circ} \mathrm{C}$ ). Furthermore, the formation of an oxygen-depleted spinel-type surface layer on the washed NCM851005 dried at temperatures near $\approx 150^{\circ} \mathrm{C}$ would also be consistent with the reduced gassing of $\mathrm{O}_{2}$ and $\mathrm{CO}_{2}$ at high $\mathrm{SOC}$ levels observed by OEMS for the washed NCM- 851005 dried at $180^{\circ} \mathrm{C}$ (Figure 4, red lines) and with its increased impedance (see Figure 5).

Effect of the drying temperature after washing on electrochemical characteristics.-If the above proposed reaction sequence were true, increasing the drying temperature of washed NCM851005 would be expected to lead to a reduced gas evolution $\left(\mathrm{O}_{2}\right.$ and $\mathrm{CO}_{2}$ ) during the first delithiation cycle and to higher cathode active material impedances, since the initially formed MOOH-like phase would gradually be decomposed at higher temperatures to less conductive $\mathrm{M}_{3} \mathrm{O}_{4}$ and ultimately to highly resistive $\mathrm{MO}$ surface layers. In order to prove this, we have carried out further OEMS and impedance measurements with washed NCM-851005 (washed twice at ambient atmosphere) dried at different temperatures: one sample was freezedried and has seen a maximum final drying temperature of $25^{\circ} \mathrm{C}(12 \mathrm{~h}$ under dynamic vacuum), while other samples were dried at $80^{\circ} \mathrm{C}$ and at $300^{\circ} \mathrm{C}$ (again $12 \mathrm{~h}$ under dynamic vacuum).

The OEMS results for the first lithiation cycle are shown in Figure 8, together with those for the pristine NCM-851005 and the twice washed NCM-851005 (under argon) dried at $180^{\circ} \mathrm{C}$ (both already shown in Figure 4). Compared to the substantial release of $\mathrm{O}_{2}(\approx 3.1 \mu \mathrm{mol} / \mathrm{g})$ and $\mathrm{CO}_{2}(\approx 171 \mu \mathrm{mol} / \mathrm{g})$ by the pristine NCM-851005 over the first lithiation cycle, Figure 8 shows a much reduced $\mathrm{O}_{2}(\approx 0.35 \mu \mathrm{mol} / \mathrm{g})$ and $\mathrm{CO}_{2}(\approx 90 \mu \mathrm{mol} / \mathrm{g})$ evolution for the washed and freeze-dried sample that experienced a maximum final drying temperature of $25^{\circ} \mathrm{C}$. At the higher drying temperature of $80^{\circ} \mathrm{C}$, a further substantial decrease of the amounts of $\mathrm{O}_{2}(\approx 0.1 \mu \mathrm{mol} / \mathrm{g})$ and $\mathrm{CO}_{2}(\approx 26 \mu \mathrm{mol} / \mathrm{g})$ can be observed, pointing toward the initial thermal decomposition of the $\mathrm{MOOH}$-like surface phase formed during washing, most likely analogous to the reported partial loss of water from $\mathrm{NiOOH}$ interlayers at $\approx 80^{\circ} \mathrm{C}$. A corresponding water desorption signal can be observed in the TGA-MS experiment shown in Figure 7 (bottom panel, red line). This trend of lowered gas evolution during the first delithiation cycle continues for drying the twice washed NCM- 851005 at $180^{\circ} \mathrm{C}$ (for $\mathrm{O}_{2}$ $\approx 0.025 \mu \mathrm{mol} / \mathrm{g}$ and for $\mathrm{CO}_{2} \approx 12 \mu \mathrm{mol} / \mathrm{g}$ ) and at $300^{\circ} \mathrm{C}$, where OEMS cannot detect any $\mathrm{O}_{2}$ evolution and reveals only very small amounts of evolved $\mathrm{CO}_{2}(\approx 6 \mu \mathrm{mol} / \mathrm{g})$. Based on the above proposed reaction sequence and the phases observed by Bak et al. ${ }^{57}$ for the thermal decomposition of delithiated NCM-811 $\left(\mathrm{Li}_{0.22} \mathrm{Ni}_{0.8} \mathrm{Co}_{0.1} \mathrm{Mn}_{0.1} \mathrm{O}_{2}\right)$, one would expect that a drying temperature of $180^{\circ} \mathrm{C}$ should be sufficiently high to produce an $\mathrm{M}_{3} \mathrm{O}_{4}$ spinel-type phase (acc. to Eq. 3), while a drying temperature of $300^{\circ} \mathrm{C}$ should result in an $\mathrm{MO}$ rocksalt-type structure (acc. to Eq. 4).

In addition to the decreasing $\mathrm{O}_{2}$ and $\mathrm{CO}_{2}$ evolution in the first lithiation cycle with increasing drying temperature for washed NCM851005 , Figure 8 also shows that the first-cycle delithiation capacity decreases with increasing drying temperature: while the washed and freeze-dried sample have essentially the same delithiation capacity as the pristine NCM-851005 $(\approx 266-270 \mathrm{mAh} / \mathrm{g}$, i.e., close to the theoretical capacity of $\approx 275 \mathrm{mAh} / \mathrm{g}$ ), the washed samples dried at $80-300^{\circ} \mathrm{C}$ have clearly lower delithiation capacities $(\approx 237-246 \mathrm{mAh} / \mathrm{g})$. For the freeze-dried sample, this suggests that the NCM particle surface still
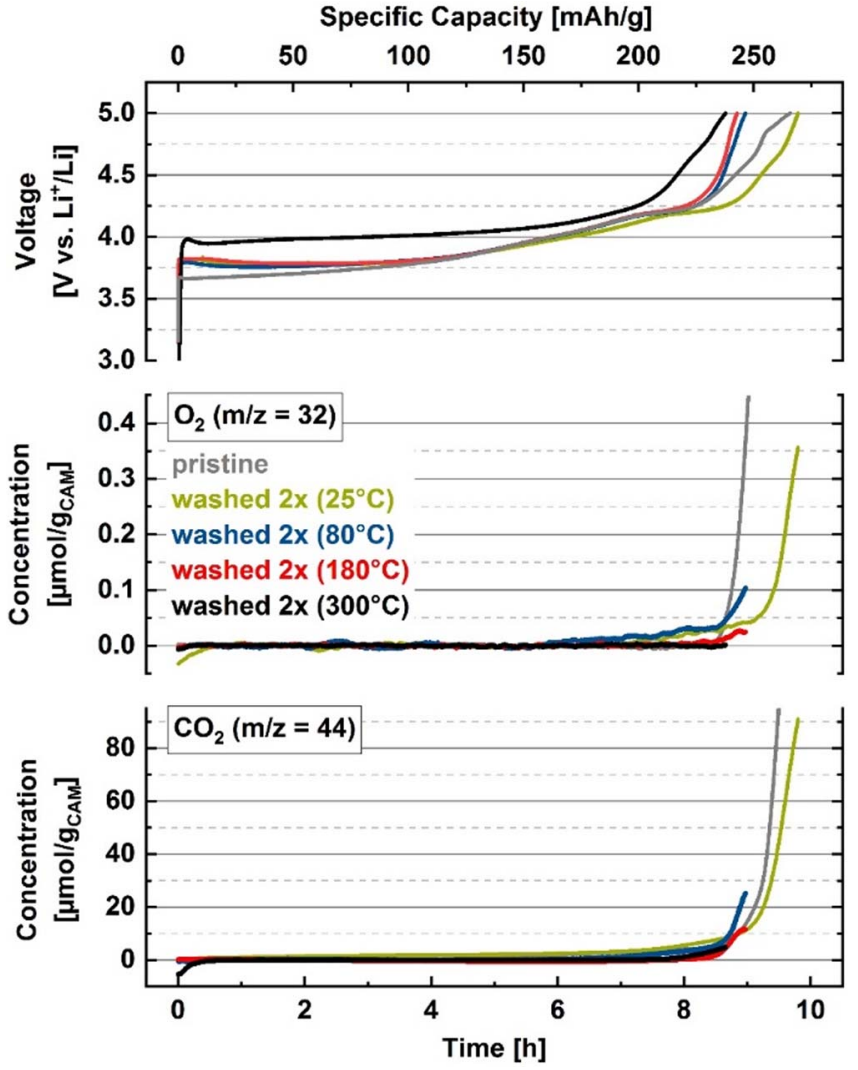

Figure 8. OEMS measurements of the first lithiation cycle to $5.0 \mathrm{~V}$ using Li/NCM-851005 half-cells with pristine and with twice washed NCM-851005 dried at different temperatures (for $12 \mathrm{~h}$ under dynamic vacuum; the material dried at $25^{\circ} \mathrm{C}$ was first freeze-dried). Upper panel: charge voltage vs. time and capacity at a C/rate of $\mathrm{C} / 10$ (referenced to $275 \mathrm{mAh} / \mathrm{g}$ theoretical delithiation capacity). Middle/lower panels: evolution of the concentrations of concomitantly evolved $\mathrm{O}_{2} / \mathrm{CO}_{2}$ given in units of $\mu \mathrm{mol} / \mathrm{g}_{\mathrm{CAM}}$. Cells were charged at $25^{\circ} \mathrm{C}$, using a metallic Li counter electrode, a glassfiber separator, and an EC-only electrolyte with $1.5 \mathrm{M} \mathrm{LiPF}_{6}$. Washing was conducted at ambient atmosphere, except for the sample dried at $180^{\circ} \mathrm{C}$ (for that, the data are the same as in Figure 4).

has a layered structure, without having trapped $\mathrm{Li}^{+}$in an inactive surface layer. On the other hand, the observed capacity loss of the washed NCM- 851005 dried at $\geq 80^{\circ} \mathrm{C}$, amounting to $\approx 20-30 \mathrm{mAh} / \mathrm{g}$, is much larger than the estimated $\leq 3 \% \mathrm{Li}^{+}$loss from the NCM particles during washing (based on the analysis of Figure 1), which would correspond to not more than $\approx 8 \mathrm{mAh} / \mathrm{g}$. Therefore, we suggest that the lower capacity stems from a phase transformation into a lithium containing spinel and/or rocksalt surface phase, resulting in a loss of cyclable material; as will be shown later, this will also be reflected in the extended charge/discharge capacities of washed/dried NCM851005. Similar surface phase transformations have been reported by Teufl et al., ${ }^{30}$ who observed a large capacity contribution from a spinel phase to the capacity of a Li- and Mn-rich NCM by a dQ/dV analysis; however, while for the Li- and Mn-rich NCMs the formed surface spinel phase can be charged/discharged reversibly at potentials of $\approx 3 \mathrm{~V} \mathrm{vs.} \mathrm{Li}^{+} / \mathrm{Li}^{58,59}$ there is no evidence of such an electrochemically active spinel-type surface phase for the here examined Ni-rich NCM. Rather, we expect that lithium can get trapped within the surface phase, leading to a loss of lithium intercalation sites by the formation of an electrochemically inactive $(\mathrm{Li}+\mathrm{M})_{3} \mathrm{O}_{4}$ spinel-type surface phase or a $(\mathrm{Li}+\mathrm{M}) \mathrm{O}$ rocksalt-type surface phase. ${ }^{57}$ As the formation of different surface phases should affect the charge-transfer resistance, we will next examine the impedance buildup of washed/dried NCMs.

The impedance of NCM-851005 cathodes using either the pristine or washed/dried NCM-851005 samples examined in Figure 8 was 

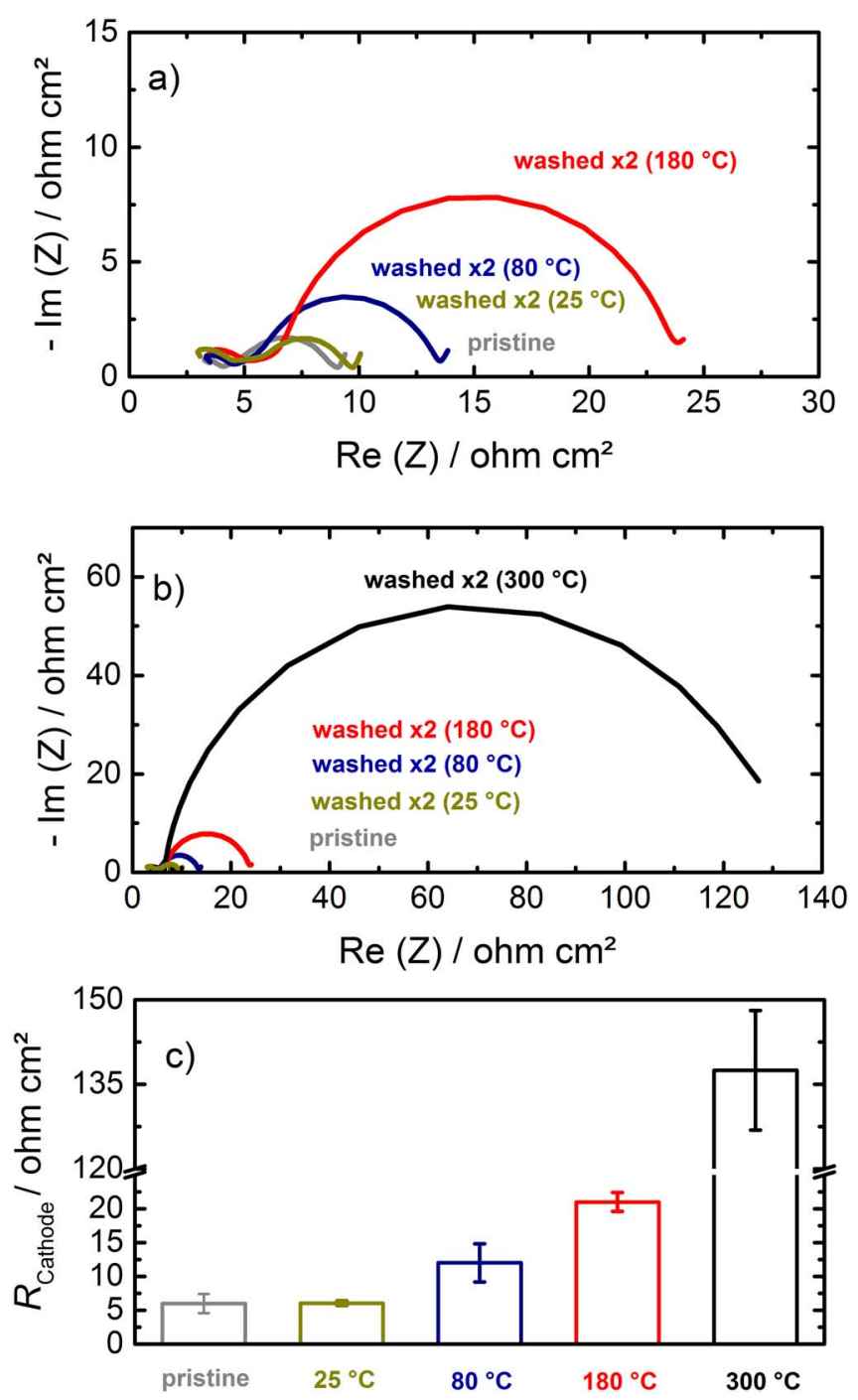

Figure 9. Cathode impedance spectra of the pristine and washed/dried NCM851005 samples shown in Figure 8, measured with a micro-reference electrode (referred to as GWRE) in a graphite//NCM-851005 full-cell configuration at $50 \%$ SOC after two formation cycles at $0.1 \mathrm{C}$ and $25^{\circ} \mathrm{C}$. a) Nyquist plot of the pristine NCM- 851005 cathode (not washed, dried at $120^{\circ} \mathrm{C}$, in gray), of the freeze-dried cathode (dried at $25^{\circ} \mathrm{C}$, in green), of the cathode dried at $80^{\circ} \mathrm{C}$ (in blue), and of the cathode dried at $180^{\circ} \mathrm{C}$ (in red). b) Zoomed-out view of panel a) in order to accommodate the impedance data for a cathode dried at $300^{\circ} \mathrm{C}$. The impedance was recorded from $100 \mathrm{kHz}$ to $100 \mathrm{mHz}$ with a perturbation of $15 \mathrm{mV}$ at $25^{\circ} \mathrm{C}$. c) Average NCM-851005 impedance (determined with a simple R/Q fit) from two independent measurements (i.e., from two cells) for each of the samples; the error bars indicate the minimum/maximum of two measurements.

determined in graphite/NCM-851005 full-cells by means of a microreference electrode (referred to as GWRE). The NCM-851005 cathode impedances $\left(R_{\text {Cathode }}\right)$ at $50 \%$ SOC after two formation cycles are shown in Figure 9. The Nyquist plot features for all NCM-851005 samples shown in Figures $9 \mathrm{a} / 9 \mathrm{~b}$ are analogous to those already discussed in the context of Figure 5. Quite clearly, the resistance of the twice washed freeze-dried NCM-851005 sample that experienced a maximum drying temperature of $25^{\circ} \mathrm{C}\left(R_{\text {Cathode }} \approx 6 \Omega \mathrm{cm}^{2}\right.$, green bar in Figure $9 \mathrm{c})$ is nearly unchanged from that of the pristine NCM-851005 $\left(R_{\text {Cathode }} \approx 5 \Omega \mathrm{cm}^{2}\right.$, gray bar). This is consistent with the expectation that the MOOH-like surface layer produced by the near-surface $\mathrm{Li}^{+} / \mathrm{H}^{+}$ion exchange of Ni-rich NCMs (see Eq. 1) will remain intact upon the removal of physisorbed water at/below room temperature, as is observed for pure NiOOH. ${ }^{56}$ As the first lithiation cycle capac- ity of the pristine and the freeze-dried NCM-851005 are essentially identical (see Figure 8, upper panel), the intercalated protons must be deintercalated upon the first charge and then either react to HF with the $\mathrm{LiPF}_{6}$ salt $^{60}$ or get reduced on the graphite anode to $\mathrm{H}_{2}$ gas. ${ }^{44}$ When increasing the drying temperature for the washed NCM-851005 to $80^{\circ} \mathrm{C}$, the temperature at which pure $\mathrm{NiOOH}$ would lose interlayer water ${ }^{56}$ and at which water desorption is also observed for the washed NCM-851005 (see Figure 7, red line in the lower panel), one can now observe an increase of the NCM-851005 impedance to a $\approx 2$-fold higher value $\left(R_{\text {Cathode }} \approx 10 \Omega \mathrm{cm}^{2}\right.$, blue bar in Figure $\left.9 \mathrm{c}\right)$ compared to pristine NCM-851005. When the material is dried at $180^{\circ} \mathrm{C}$, the cathode resistance increases by another factor of two to $R_{\text {Cathode }} \approx 20$ $\Omega \mathrm{cm}^{2}$ (red bar), which can be explained by the expected formation of an $\mathrm{M}_{3} \mathrm{O}_{4}$ spinel-like surface layer according to Eq. 3. Interestingly, when the washed NCM- 851005 is dried at $300^{\circ} \mathrm{C}$, i.e., above the temperature for which we had observed a substantial loss of oxygen in the TGA-MS experiment (Figure 7), its impedance drastically increases to $R_{\text {Cathode }} \approx 130 \Omega \mathrm{cm}^{2}$ (black bar).

Quite clearly, the above discussed impedance increase of washed NCM-851005 with drying temperature is amazingly consistent with the temperature-dependent phase transformations of delithiated NCM$811\left(\mathrm{Li}_{0.22} \mathrm{Ni}_{0.8} \mathrm{Co}_{0.1} \mathrm{Mn}_{0.1} \mathrm{O}_{2}\right)$ reported by Bak et al., ${ }^{57}$ who showed the formation of a disordered $\mathrm{M}_{3} \mathrm{O}_{4}$-type spinel at $\approx 135-150^{\circ} \mathrm{C}$, which upon further heating would convert to an $\mathrm{MO}$ rocksalt phase that was fully formed at $\approx 360^{\circ} \mathrm{C}$. This is reflected by the evolution of the impedance of washed NCM-851005 dried at different temperatures (Figure 9c): i) essentially unchanged impedance compared to pristine NCM-851005 when dried at low temperatures (here $25^{\circ} \mathrm{C}$ ); ii) a significant impedance increase with drying temperatures between approximately $80-180^{\circ} \mathrm{C}$, due to surface-spinel formation; and, iii) a dramatic impedance increase for drying at $300^{\circ} \mathrm{C}$, due to the formation of a highly resistive rocksalt structure on the surface. Thus, these cathode impedance measurements underline that the drying temperature for washed Ni-rich NCMs is the main driver for reducing their gassing in a graphite/NCM full-cell, but also for increasing their impedance.

Influence of washing/drying on the full-cell cycling performance at $25^{\circ} \boldsymbol{C}$.-Following the above described impedance measurements (Figure 9) conducted after formation ( 2 cycles at $\mathrm{C} / 10$ and a subsequent charge to $50 \%$ SOC), the graphite/NCM-851005 full-cells were cycled for another 198 cycles with a charge rate of $\mathrm{C} / 2$ to $4.2 \mathrm{~V}$ (CCCV mode, with a $\mathrm{CV}$ phase to $\mathrm{C} / 20$ ) and a discharge rate of $1 \mathrm{C}$ to $3.0 \mathrm{~V}$ (CC mode). The results of this test are shown in Figure 10, revealing that the discharge capacities and the capacity retention of the pristine NCM-851005 are superior to that of the washed NCM-851005, and that both capacities and capacity retention are the worse the higher the drying temperature.

Even during the first two formation cycles at $\mathrm{C} / 10$ with a $4.2 \mathrm{~V}$ upper cut-off potential (cycles 1 and 2 in Figure 10), the discharge capacities of the washed NCM-851005 cathodes are lower than those of the pristine material, particularly for the washed material dried at $300^{\circ} \mathrm{C}$ (see $2^{\text {nd }}$ and $3^{\text {rd }}$ columns of Table I). This reflects the lower firstcharge capacities of the washed NCM-851005 cathodes already noted for the half-cell experiments shown in Figure 8, presumably due to the loss of lithium intercalation sites by the formation of an electrochemically inactive surface layer. We believe that the latter is responsible for the increasing cathode impedance of the washed NCM-851005 with increasing drying temperature (see Figure 9c), which manifests itself by an increasing discharge capacity loss when increasing the discharge rate from $\mathrm{C} / 10$ in the $2^{\text {nd }}$ cycle to $1 \mathrm{C}$ in the $3^{\text {rd }}$ cycle, namely by $10 \mathrm{mAh} / \mathrm{g}$ ( $\equiv 5 \%$ ) for the pristine NCM-851005 up to $40 \mathrm{mAh} / \mathrm{g}$ $(\equiv 31 \%)$ for the washed NCM-851005 dried at $300^{\circ} \mathrm{C}$ (see $5^{\text {th }}$ column of Table I).

While the lower initial discharge capacities of the washed/dried NCM-851005 can be rationalized on the basis of a loss of lithium intercalation sites and by an increased cathode impedance of the washed/dried materials, it does not explain the observed strong increase of the capacity fading upon extended cycling with an increase in the drying temperature of the washed NCM-851005 (see last 
Table I. Average discharge capacities determined from Figure 10 for the graphite/NCM-851005 full-cells with cathodes based on pristine NCM851005 or on washed $\mathrm{NCM}-851005$ dried at either $80^{\circ} \mathrm{C}, 180^{\circ} \mathrm{C}$, or $300^{\circ} \mathrm{C}$. From left to right: discharge capacity of the $2^{\text {nd }} \mathrm{C} / 10$ formation cycle (cycle 2 in Figure 10); capacity loss of the washed NCM-851005 cathodes compared to pristine NCM-851005; discharge capacity of the $1^{\text {st }}$ cycle at 1C (cycle 3 in Figure 10); discharge capacity loss when switching from C/10 to 1C (cycles 2 and 3 in Figure 10); discharge capacity loss over 198 cycles at $1 \mathrm{C}$ discharge rate (cycles 3 to 200 in Figure 1; charge rate at $\mathrm{C} / 2$ ).

\begin{tabular}{|c|c|c|c|c|c|}
\hline NCM-851005 cath. & $\begin{array}{l}2^{\text {nd }} \mathrm{C} / 10 \text { disch. } \\
\quad \text { in } \mathrm{mAh} / \mathrm{g}\end{array}$ & $\begin{array}{l}\text { loss vs. pristine } \\
\text { in } \mathrm{mAh} / \mathrm{g} \text { or }(\%)\end{array}$ & $\begin{array}{l}1^{\text {st }} 1 \mathrm{C} \text { disch. } \\
\text { in } \mathrm{mAh} / \mathrm{g}\end{array}$ & $\begin{array}{l}\text { loss } \mathrm{C} / 10 \rightarrow 1 \mathrm{C} \\
\text { in } \mathrm{mAh} / \mathrm{g} \text { or }(\%)\end{array}$ & $\begin{array}{c}\text { loss over } 1981 \mathrm{C} \text { cycles } \\
\text { in } \mathrm{mAh} / \mathrm{g} \text { or }(\%)\end{array}$ \\
\hline Pristine & 188 & & 178 & $10(5 \%)$ & $21(12 \%)$ \\
\hline washed $2 \mathrm{x}\left(80^{\circ} \mathrm{C}\right)$ & 178 & $10(6 \%)$ & 158 & $20(11 \%)$ & $32(20 \%)$ \\
\hline washed $2 \mathrm{x}\left(180^{\circ} \mathrm{C}\right)$ & 175 & $13(7 \%)$ & 147 & $28(16 \%)$ & $38(25 \%)$ \\
\hline washed $2 \mathrm{x}\left(300^{\circ} \mathrm{C}\right)$ & 130 & $58(45 \%)$ & 90 & $40(31 \%)$ & $83(92 \%)$ \\
\hline
\end{tabular}

column of Table I). The cause of this is found by taking a closer look into the evolution of the voltage vs. capacity profiles, comparing the $3^{\text {rd }}$ cycle with a $1 \mathrm{C}$ discharge rate with that of the $28^{\text {th }}$ cycle at $1 \mathrm{C}$ for the cathodes with both the pristine NCM-851005 and the washed NCM-851005 dried at $300^{\circ} \mathrm{C}$, whose discharge capacity has already dropped by $\approx 65 \%$ at this point. As shown in Figure $10 \mathrm{~b}$, the overpotential of the cathode with the pristine NCM-851005, indicated by width of the voltage profiles, as well as the length of the CV phase remain essentially constant between the $1^{\text {st }}$ (solid gray line) and the $25^{\text {th }}$ cycle (dashed gray line) at $1 \mathrm{C}$ discharge. This is in stark contrast to the cathode with the washed NCM- 851005 dried at $300^{\circ} \mathrm{C}$, for which the apparent overpotential as well as the length of the $\mathrm{CV}$ phase increase dramatically (black lines). While we unfortunately had not recorded the cathode impedance after the 200 cycles, the evolution of the voltage profiles clearly indicates that the surface layer formed upon
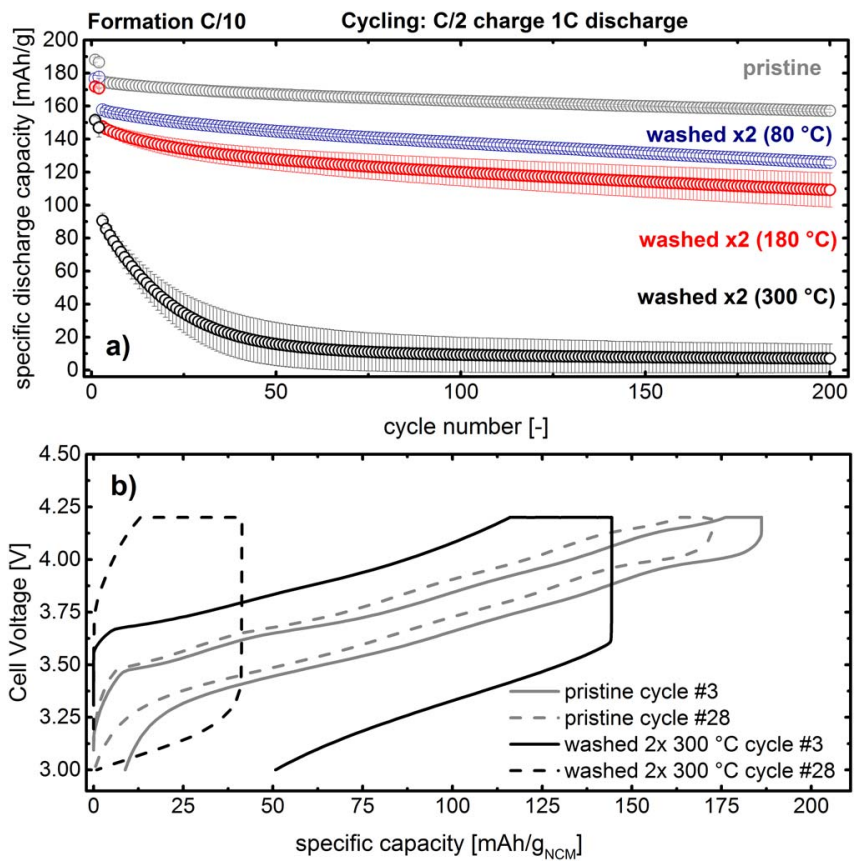

Figure 10. Charge/discharge cycling test of the graphite/NCM-851005 fullcells with a micro-reference electrode shown in Figure 9 and with LP57 electrolyte. After 2 formation cycles at $\mathrm{C} / 10$ (shown as the first two cycles), the cycling is carried out with a $\mathrm{C} / 2$ charge to $4.2 \mathrm{~V}$ (CCCV mode, with a cutoff for the $\mathrm{CV}$ phase of $\mathrm{C} / 20$ ) and with a $1 \mathrm{C}$ discharge to $3.0 \mathrm{~V}$ (CC mode). a) Specific discharge capacities of the pristine NCM- 851005 cathode (not washed, dried at $120^{\circ} \mathrm{C}$, in gray), and of the washed $\mathrm{NCM}-851005$ cathodes dried at $80^{\circ} \mathrm{C}$ (in blue), at $180^{\circ} \mathrm{C}$ (in red), or at $300^{\circ} \mathrm{C}$ (in black). b) Full-cell voltage vs. capacity profiles of the $3^{\text {rd }}$ and of the $28^{\text {th }}$ cycle at $\mathrm{C} / 2$ charge and 1C discharge of the pristine NCM-851005 cathode (in gray) and of the washed NCM-851005 cathode dried at $300^{\circ} \mathrm{C}$. The data points represent the average from two measurements and the error bars correspond to the minimum/maximum value of two measurements. washing/drying according to the here used procedures is unstable and that its impedance increases with extended cycling. Thus, in contrast to the positive effect of washing/drying on the capacity retention of LCO reported by Jeong et al., no such such benefits can be observed for NCM-851005 under the here explored washing/drying conditions.

\section{Conclusions}

In this study, we have analyzed the washing process of a nickel-rich cathode active material (NCM 851005) in pure water at room temperature. We showed that $\mathrm{Li}_{2} \mathrm{CO}_{3}$ surface contaminants are removed by a simple dissolution mechanism, so that it cannot be detected anymore in subsequent washing step if it is conducted in a $\mathrm{CO}_{2}$-free environment. On the other hand, $\mathrm{LiOH}$ is formed continuously during washing due to a near-surface $\mathrm{Li}^{+} / \mathrm{H}^{+}$ion exchange, so that the fraction of $\mathrm{LiOH}$ ascribable to the dissolution of $\mathrm{LiOH}$ surface contaminants cannot be quantified. The washed samples were analyzed by on-line electrochemical mass spectrometry (OEMS) in terms of gassing, revealing that the release of $\mathrm{O}_{2}$ and $\mathrm{CO}_{2}$ above $80 \%$ SOC decreases substantially as the drying temperature of the washed NCM-851005 is increased from $25^{\circ} \mathrm{C}$ to $300^{\circ} \mathrm{C}$, along with the cathode impedance. With a detailed TGA-MS analysis we could deconvolute the evolution of oxygen and water during the drying process, which is consistent with a near-surface $\mathrm{Li}^{+} / \mathrm{H}^{+}$ion exchange during washing and with the formation of a $\mathrm{MOOH}$-like surface structure, which is then thermally decomposed in an oxygen-deficient surface layer. These findings demonstrate that the drying temperature is a critical step when washing Ni-rich NCMs.

\section{Acknowledgment}

Financial support by the BASF SE through its Research Network on Electrochemistry and Batteries is gratefully acknowledged.

\section{ORCID}

Daniel Pritzl (D) https://orcid.org/0000-0002-9029-107X

Tobias Teufl (1) https://orcid.org/0000-0001-5889-5204

Benjamin Strehle (1D https://orcid.org/0000-0001-8878-1160

Johannes Sicklinger (1D https://orcid.org/0000-0003-2815-993X

\section{References}

1. D. Larcher and J. M. Tarascon, Nat. Chem., 7(1), 19 (2015)

2. D. Andre, S.-J. Kim, P. Lamp, S. F. Lux, F. Maglia, O. Paschos, and B. Stiaszny, J. Mater. Chem. A, 3(13), 6709 (2015).

3. G. E. Blomgren, J. Electrochem. Soc., 164(1), A5019 (2016).

4. M.-H. Kim, H.-S. Shin, D. Shin, and Y.-K. Sun, J. Power Sources, 159(2), 1328 (2006).

5. P. Rozier and J. M. Tarascon, J. Electrochem. Soc., 162(14), A2490 (2015).

6. R. Jung, R. Morasch, P. Karayaylali, K. Phillips, F. Maglia, C. Stinner, Y. Shao-Horn, and H. A. Gasteiger, J. Electrochem. Soc., 165(2), A132 (2018).

7. I. A. Shkrob, J. A. Gilbert, P. J. Phillips, R. Klie, R. T. Haasch, J. Bareño, and D. P. Abraham, J. Electrochem. Soc., 164(7), A1489 (2017).

8. J. Sicklinger, M. Metzger, H. Beyer, D. Pritzl, and H. A. Gasteiger, J. Electrochem. Soc., 166(12), A2322 (2019). 
9. N. V. Faenza, L. Bruce, Z. W. Lebens-Higgins, I. Plitz, N. Pereira, L. F. J. Piper, and G. G. Amatucci, J. Electrochem. Soc., 164(14), A3727 (2017).

10. J. Paulsen, H.-K. Park, and Y.-H. Kwon, US 2009/0224201 Al (2009).

11. J. Paulsen and J. H. Kim, WO 2012/107313 Al (2012).

12. D.-H. Kim and J. Paulsen, United States Pat. Appl., 2016036557, WO 2015/128722 Al (2015).

13. J. Paulsen, H. P. Hong, and H. S. Ahn, WO 2015/036882 A2 (2015).

14. J. Paulsen, H. P. Hong, and J. D. Oh, WO 2016/055911 Al (2016).

15. J. R. Dahn, R. Fong, and U. v. Sacken, US 2, 264, 201 (1993).

16. G. V. Zhuang, G. Chen, J. Shim, X. Song, P. N. Ross, and T. J. Richardson, J.Power Sources, 134(2), 293 (2004).

17. J. Kim, H. Lee, H. Cha, M. Yoon, M. Park, and J. Cho, Adv. Ener. Mater, 8(6) (2018)

18. Y. Kim, J. Mater. Sci., 48(24), 8547 (2013).

19. S. E. Renfrew and B. D. McCloskey, J. Am. Chem. Soc., 139(49), 17853 (2017).

20. R. Jung, P. Strobl, F. Maglia, C. Stinner, and H. A. Gasteiger, J. Electrochem. Soc., 165(11), A2869 (2018).

21. M. Metzger, B. Strehle, S. Solchenbach, and H. A. Gasteiger, J. Electrochem. Soc., 163(7), A1219 (2016).

22. H.-J. Noh, S. Youn, C. S. Yoon, and Y.-K. Sun, J. Power Sources, 233, 121 (2013).

23. S. Arimoto, K. Tsuruta, R. Leblanc, R. Melsert, and US 2017/02946521 A1 (2017).

24. J. Kim, Y. Hong, K. S. Ryu, M. G. Kim, and J. Cho, Electrochem. Solid State Lett., 9, A19 (2006).

25. Y. Kim, J. Solid State Electrochem., 17(7), 1961 (2013).

26. X. Xiong, Z. Wang, P. Yue, H. Guo, F. Wu, J. Wang, and X. Li, J. Power Sources, 222, 318 (2013).

27. R. Jung, M. Metzger, F. Maglia, C. Stinner, and H. A. Gasteiger, J. Electrochem. Soc., 164(7), A1361 (2017).

28. D. Streich, C. Erk, A. Guéguen, P. Müller, F.-F. Chesneau, and E. J. Berg, J. Phys. Chem. C, 121(25), 13481 (2017).

29. R. Jung, M. Metzger, F. Maglia, C. Stinner, and H. A. Gasteiger, J. Phys. Chem. Lett., 8(19), 4820 (2017)

30. T. Teufl, B. Strehle, P. Müller, H. A. Gasteiger, and M. A. Mendez, J. Electrochem. Soc., 165(11), A2718 (2018).

31. J. Sicklinger, H. Beyer, L. Hartmann, F. Riewald, and H. A. Gasteiger, mansucript in preparation.

32. H. Sclar, J. Sicklinger, E. M. Ericson, S. Maiti, J. Grinblat, M. Talianker, L. Burstein, H. Beyer, G. Avruschenko, H. A. Gasteiger, B. Markovsky, and D. Aurbach, manuscript in preparation.

33. Z. Chen, J. Wang, J. Huang, T. Fu, G. Sun, S. Lai, R. Zhou, K. Li, and J. Zhao, J. Power Sources, 363, 168 (2017).

34. Y. Cho, S. Lee, Y. Lee, T. Hong, and J. Cho, Adv. Ener. Mater, 1(5), 821 (2011).

35. Y.-K. Sun, S.-T. Myung, B.-C. Park, J. Prakash, I. Belharouak, and K. Amine, Nat. Mater, 8, 320 (2009).
36. D. Larcher, M. R. Palacin, G. G. Amatucci, and J. M. Tarascon, J. Electrochem. Soc., 144, 408 (1997)

37. G. G. Amatucci, J. M. Tarascon, D. Larcher, and L. C. Klein, Solid State Ionics, 84(3), 169 (1996).

38. B. Strehle, K. Kleiner, R. Jung, F. Chesneau, M. Mendez, H. A. Gasteiger, and M. Piana, J. Electrochem. Soc., 164(2), A400 (2017).

39. N. Tsiouvaras, S. Meini, I. Buchberger, and H. A. Gasteiger, J. Electrochem. Soc., 160(3), A471 (2013).

40. S. Solchenbach, D. Pritzl, E. J. Y. Kong, J. Landesfeind, and H. A. Gasteiger, J. Electrochem. Soc., 163(10), A2265 (2016).

41. R. Moshtev, J. Power Sources, 81, 434 (1999).

42. S. Jeong, J. Kim, and J. Mun, J. Electrochem. Soc., 166(3), A5038 (2019).

43. M. Metzger, C. Marino, J. Sicklinger, D. Haering, and H. A. Gasteiger, J. Electrochem. Soc., 162(7), A1123 (2015).

44. M. Metzger, B. Strehle, S. Solchenbach, and H. A. Gasteiger, J. Electrochem. Soc., 163(5), A798 (2016).

45. B. Zhang, M. Metzger, S. Solchenbach, M. Payne, S. Meini, H. A. Gasteiger, A. Garsuch, and B. L. Lucht, J. Phys. Chem. C, 119(21), 11337 (2015).

46. S. Solchenbach, G. Hong, A. T. S. Freiberg, R. Jung, and H. A. Gasteiger, J. Electrochem. Soc., 165(14), A3304 (2018).

47. J. Wandt, A. T. S. Freiberg, A. Ogrodnik, and H. A. Gasteiger, Materials Today, 21, 218 (2018).

48. K. Luo, M. R. Roberts, R. Hao, N. Guerrini, D. M. Pickup, Y.-S. Liu, K. Edström, J. Guo, A. V. Chadwick, L. C. Duda, and P. G. Bruce, Nat. Chem., 8, 684 (2016).

49. S. E. Renfrew and B. D. McCloskey, ACS Appl. Ener. Mater., 2(5), 3762 (2019).

50. S. E. Renfrew, L. A. Kaufman, and B. D. McCloskey, ACS Appl. Mater. Inter., 11(38), 34913 (2018).

51. A. T. S. Freiberg, M. K. Roos, J. Wandt, R. de Vivie-Riedle, and H. A. Gasteiger, $J$. Phys. Chem. A, 122(45), 8828 (2018).

52. F. Lin, I. M. Markus, D. Nordlund, T.-C. Weng, M. D. Asta, H. L. Xin, and M. M. Doeff, Nat. Commun., 5, 3529 (2014).

53. T. Teufl, D. Pritzl, S. Solchenbach, H. A. Gasteiger, and M. A., J. Electrochem. Soc., 166(6), A1275 (2019).

54. J. Landesfeind, D. Pritzl, and H. A. Gasteiger, J. Electrochem. Soc., 164(7), A1773 (2017).

55. H. S. Liu, Electrochem. Solid State Lett., 7(7), A190 (2004).

56. J. Pan, Y. Sun, P. Wan, Z. Wang, and X. Liu, Electrochem. Commun., 7(8), 857 (2005).

57. S. M. Bak, E. Hu, Y. Zhou, and X. Yu, ACS Appl. Mater. Inter, 6(24), 22594 (2014).

58. P. G. Bruce, A. R. Armstrong, and R. L. Gitzendanner, J. Mater. Chem., 9, 193 (1998).

59. M. M. Thackeray, Prog. Solid State Chem., 25, 1 (1997).

60. S. Solchenbach, M. Metzger, M. Egawa, H. Beyer, and H. A. Gasteiger, J. Electrochem. Soc., 165(13), A3022 (2018). 